\title{
RIPK1 and death receptor signaling drive biliary damage and early liver tumorigenesis in mice with chronic hepatobiliary injury
}

\author{
Santosh Krishna-Subramanian $\mathbb{1}^{1,2,3}$ - Stephan Singer ${ }^{4,5} \cdot$ Marietta Armaka $\mathbb{1}^{6}$ - Jesus M. Banales ${ }^{7} \cdot$ Kerstin Holzer $^{5}$. \\ Peter Schirmacher ${ }^{4}$ Henning Walczak $\mathbb{D}^{8} \cdot$ George Kollias $\mathbb{D}^{6,9} \cdot$ Manolis Pasparakis $\mathbb{D}^{1,2,3} \cdot$ Vangelis Kondylis $\mathbb{D} \mathbb{D}^{1,2,3}$
}

Received: 6 November 2018 / Revised: 12 March 2019 / Accepted: 26 March 2019 / Published online: 15 April 2019

(c) ADMC Associazione Differenziamento e Morte Cellulare 2019

\begin{abstract}
Hepatocyte apoptosis is intrinsically linked to chronic liver disease and hepatocarcinogenesis. Conversely, necroptosis of hepatocytes and other liver cell types and its relevance for liver disease is debated. Using liver parenchymal cell (LPC)specific TGF-beta-activated kinase 1 (TAK1)-deficient $\left(\mathrm{TAK} 1^{\mathrm{LPC}-\mathrm{KO}}\right.$ ) mice, which exhibit spontaneous hepatocellular and biliary damage, hepatitis, and early hepatocarcinogenesis, we have investigated the contribution of apoptosis and necroptosis in hepatocyte and cholangiocyte death and their impact on liver disease progression. Here, we provide in vivo evidence showing that TAK1-deficient cholangiocytes undergo spontaneous necroptosis induced primarily by TNFR1 and dependent on RIPK1 kinase activity, RIPK3, and NEMO. In contrast, TAK1-deficient hepatocytes die by FADD-dependent apoptosis, which is not significantly inhibited by LPC-specific RIPK1 deficiency, inhibition of RIPK1 kinase activity, RIPK3 deficiency or combined LPC-specific deletion of TNFR1, TRAILR, and Fas. Accordingly, normal mouse cholangiocytes can undergo necroptosis, while primary hepatocytes are resistant to it and die exclusively by apoptosis upon treatment with cell death-inducing stimuli in vitro, likely due to the differential expression of RIPK3. Interestingly, the genetic modifications that conferred protection from biliary damage also prevented the spontaneous lethality that was often observed in TAK $1{ }^{\mathrm{LPC}-\mathrm{KO}}$ mice. In the presence of chronic hepatocyte apoptosis, preventing biliary damage delayed but did not avert hepatocarcinogenesis. On the contrary, inhibition of hepatocyte apoptosis fully prevented liver tumorigenesis even in mice with extensive biliary damage. Altogether, our results suggest that using RIPK1 kinase activity inhibitors could be therapeutically useful for cholestatic liver disease patients.
\end{abstract}

These authors contributed equally: Manolis Pasparakis, Vangelis

Kondylis

Edited by G. Melino

Supplementary information The online version of this article (https:// doi.org/10.1038/s41418-019-0330-9) contains supplementary material, which is available to authorized users.

Vangelis Kondylis

e.kondylis@uni-koeln.de

1 Institute for Genetics, University of Cologne, D-50674 Cologne, Germany

2 Cologne Excellence Cluster on Cellular Stress Responses in Aging-Associated Diseases (CECAD), University of Cologne, Cologne, Germany

3 Center for Molecular Medicine (CMMC), University of Cologne, Cologne, Germany

4 Institute of Pathology, University Hospital Heidelberg, Heidelberg, Germany

\section{Introduction}

Hepatocellular carcinoma (HCC) arises predominantly in a chronic setting of liver injury, hepatocyte proliferation, inflammation, and fibrosis. Liver cell death is a potent

5 Institute of Pathology, University Medicine Greifswald, Greifswald, Germany

6 Division of Immunology, Biomedical Sciences Research Center "Alexander Fleming", Vari, Athens, Greece

7 Department of Liver and Gastrointestinal Diseases, Biodonostia Health Research Institute, Donostia University Hospital, University of the Basque Country (UPV/EHU), CIBERehd, Ikerbasque, San Sebastian, Spain

8 Centre for Cell Death, Cancer and Inflammation, Department of Cancer Biology, UCL Cancer Institute, University College London, London, United Kingdom

9 Department of Physiology, School of Medicine, National and Kapodistrian University of Athens, Athens, Greece 
trigger of acute and chronic liver disease [1-3], and while a wealth of studies have demonstrated that apoptosis promotes liver disease and HCC in mice and humans [4-11], the contribution of necroptosis remains controversial [12].

Receptor Interacting Protein Kinase 1 (RIPK1) has emerged as a key molecule that promotes apoptosis and necroptosis through its kinase activity, and cell survival via scaffolding functions. Its functions are best characterized in tumor necrosis factor receptor 1 (TNFR1) signaling [3, 13, 14]. Upon TNFR1 activation, RIPK1 forms Complex I together with TNFR1-associated death domain protein (TRADD), TNFR-associated factor 2 (TRAF2), cellular inhibitors of apoptosis 1 and 2 (cIAP1/2), and linear ubiquitin chain assembly complex (LUBAC). RIPK1 ubiquitination by cIAPs and LUBAC mediates the recruitment of transforming growth factor beta (TGF $\beta$ )-activated kinase 1 (TAK1)/TAK1-binding protein 2/3 (TAB2/3) complex, as well as the inhibitor of nuclear factor $\kappa \mathrm{B}$ (IКB) kinase (IKK) complex, consisting of the IKK1/IKK $\alpha$ and IKK2/IKK $\beta$ kinases and the regulatory subunit NEMO/IKK $\gamma$. TAK1 and IKK complexes promote cell survival by activating nuclear factor $\mathrm{\kappa B}(\mathrm{NF}-\mathrm{\kappa B})$ signaling. Additionally, direct or indirect phosphorylation of RIPK1 by TAK1, IKK1/2, and TBK1/ IKK $\varepsilon$ was shown to protect from TNF-induced cell death $[9,13-17]$. In the absence of this prosurvival phosphorylation, RIPK1 is autophosphorylated and nucleates the formation of Complex IIb that also includes Fas-associated protein with death domain (FADD) and Caspase-8, thereby triggering apoptosis. When Caspase- 8 activity is inhibited, RIPK1 together with RIPK3 and mixed lineage kinase-like (MLKL) form the necrosome that induces necroptosis. Necroptosis induction is cell-specific and depends on RIPK3 expression. Finally, FADD/Caspase-8-mediated apoptosis can also proceed through Complex IIa, the formation of which is RIPK1-independent but TRADDdependent [3].

Studies in mice lacking NEMO or TAK1 in liver parenchymal cells (LPCs) provided important insights into the role of cell death in chronic liver disease and cancer. Mice with LPC-specific ablation of NEMO $\left(\mathrm{NEMO}^{\mathrm{LPC}-\mathrm{KO}}\right)$ develop spontaneous hepatocellular damage, steatohepatitis and HCC after 9-12 months. The pathology of NEMO ${ }^{\mathrm{LPC}-\mathrm{KO}}$ mice is driven by RIPK1 kinase activity/FADD/Caspase-8mediated hepatocyte apoptosis [4-7]. TAK1 ${ }^{\mathrm{LPC}-\mathrm{KO}}$ mice also develop hepatocellular damage, but additionally, they exhibit biliary damage, lethal cholestasis, and early-onset hepatocarcinogenesis [18]. While HCCs can be identified in $\mathrm{TAK}^{\mathrm{LPC}-\mathrm{KO}}$ mice as early as $16-20$ weeks, only small dysplastic foci are detected in NEMO ${ }^{\mathrm{LPC}-\mathrm{KO}}$ mice of similar age $[4,18]$. Considering that TAK1 and NEMO are both essential for NF- $\mathrm{KB}$ activation and pro-survival RIPK1 phosphorylation, the aggravated phenotype in TAK1 $1^{\mathrm{LPC}-\mathrm{KO}}$ mice likely reflects additional TAK1 functions.
TAK1 ${ }^{\text {LPC-KO }}$ mice are generated using Alfp-Cre recombinase expression that leads to TAK1 ablation both in hepatocytes and cholangiocytes [18, 19]. Interestingly, $\mathrm{TAK} 1^{\Delta \mathrm{Hep}}$ mice, where TAK1 is specifically removed from hepatocytes using Alb-Cre, show chronic hepatocellular damage, compensatory proliferation, hepatitis and fibrosis, but have no biliary damage and develop HCC only at 1 year of age $[18,20]$. These differences have suggested that biliary damage promotes early tumorigenesis in TAK $1^{\mathrm{LPC}-\mathrm{KO}}$ mice.

In this study, we have used TAK $1^{\mathrm{LPC}-\mathrm{KO}}$ mice to dissect genetically the relative contribution of key molecules regulating apoptosis and necroptosis in hepatocellular and biliary damage and hepatocarcinogenesis.

\section{Results}

\section{FADD drives hepatocyte apoptosis and hepatocarcinogenesis in TAK $1^{\text {LPC-KO }}$ mice}

To investigate the role of apoptosis and necroptosis in chronic hepatocellular and biliary damage and hepatocarcinogenesis, we generated TAK $1^{\mathrm{LPC}-\mathrm{KO}}$ mice. As previously reported [18], 6-week-old TAK1 $1^{\text {LPC-KO }}$ mice developed severe liver disease characterized by increased hepatocyte apoptosis and biliary damage, as indicated by elevated serum ALT, total bilirubin and Alkaline Phosphatase (ALP) levels, increased cleaved Caspase-3 (CC3) and necrotic foci in periportal areas (Fig. 1a, b, d, e, and S1A). Liver damage induced a strong regenerative response marked by increased number of Ki-67 ${ }^{+}$hepatocytes and cholangiocytes, expansion of Cytokeratin 19 (CK19)-positive cholangiocytes and hepatic progenitor cells (known as ductular reaction) and elevated levels of Cyclin D1 and the oncofetal marker afp (Fig. 1d-f). Furthermore, we observed strong inflammation, evidenced by increased Tnf mRNA expression and $\mathrm{F} 4 / 80^{+}$macrophage infiltration both at periportal areas and in the liver parenchyma, and increased fibrosis detected by Sirius Red staining and $T g f b l \mathrm{mRNA}$ expression (Fig. If and S1B-C). At this age, TAK1 $1^{\text {LPC-KO }}$ mice exhibited an abnormal liver appearance with many macroscopically visible small nodules (Fig. 1c).

To assess the effect of FADD-dependent apoptosis on the liver damage of TAK $1^{\text {LPC-KO }}$ mice, we generated mice deficient for FADD and TAK1 in LPCs. Similar to TAK1 $1^{\text {LPC-KO }}$ Caspase- $8^{\text {LPC-KO mice }}$ [8], TAK1 $1^{\text {LPC-KO }}$ FADD $^{\text {LPC-KO }}$ mice had smooth liver appearance and significant reduction in serum ALT levels, while the number of apoptotic and proliferating hepatocytes, inflammation, fibrosis and ductular reaction were nearly down to the levels of control mice (Fig. 1 and S1B-C). However, TAK1 ${ }^{\text {LPC-KO }}$ FADD $^{\text {LPC-KO }}$ mice still exhibited necrotic foci at periportal areas, while additional scattered necrotic lesions were 
A

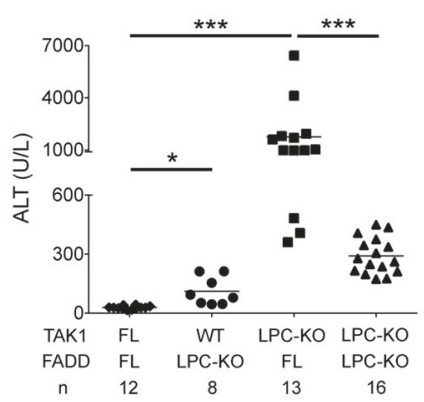

C

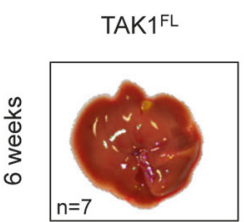

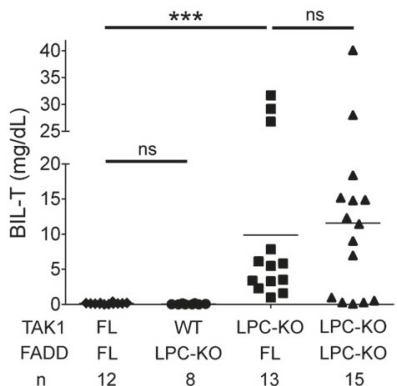

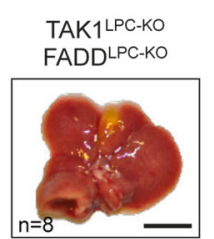

TAK1 1 LPC-KO

D
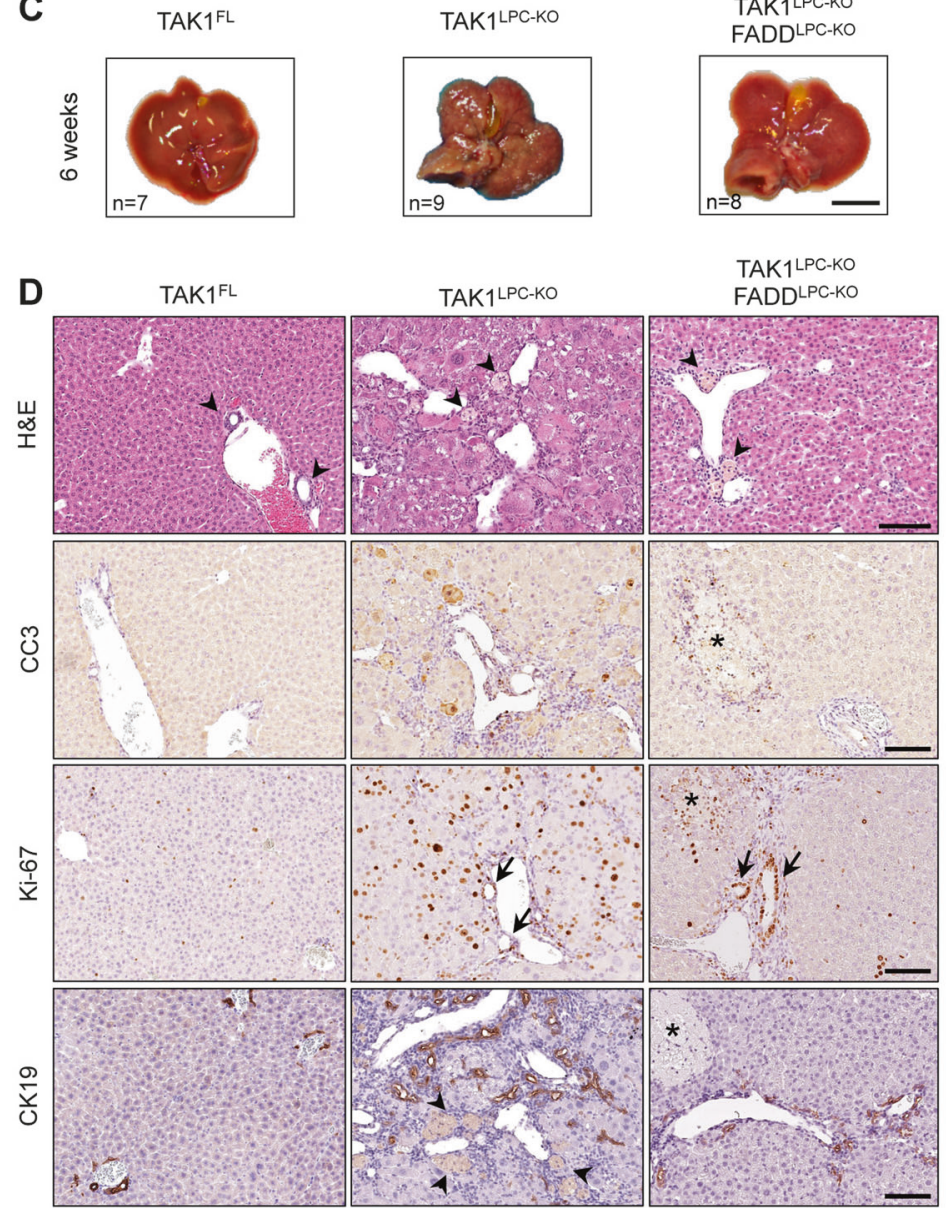

TAK $1 P C-K O$
$\mathbf{F}$
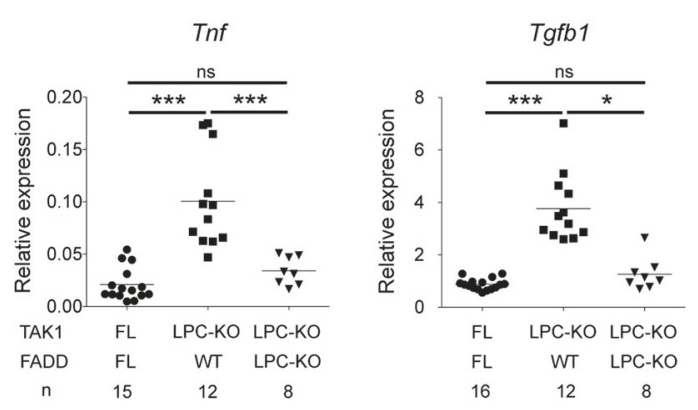

detected in the liver parenchyma (Fig. 1d), as reported in FADD $^{\text {LPC-KO }}$ and Caspase- $8^{\text {LPC-KO }}$ mice $[5,6]$. Despite the drastic decrease in hepatocellular damage, FADD ablation

\section{B}

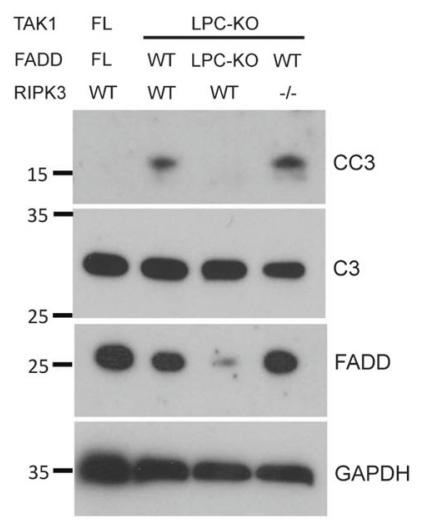

E
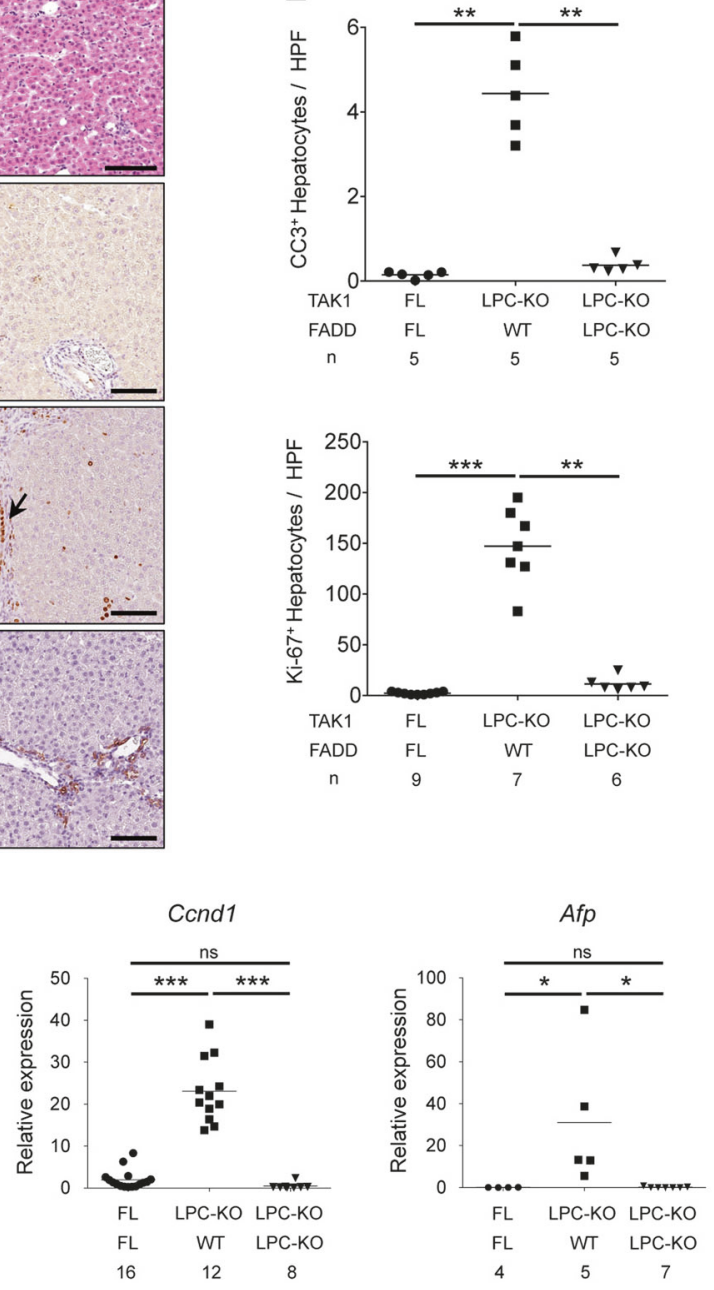

did not significantly reduce biliary damage, with only one third of TAK1 $1^{\text {LPC-KO }}$ FADD ${ }^{\text {LPC-KO }}$ mice showing low bilirubin and ALP levels (Fig. 1a and S1A). 
Fig. 1 FADD is required for hepatocellular but not biliary damage in TAK1 ${ }^{\mathrm{LPC}-\mathrm{KO}}$ mice. a Serum ALT and total Bilirubin levels in 6-weekold mice. b Immunoblot analysis of total (C3) and cleaved Caspase-3 (CC3) in whole liver lysates from 6-week-old mice with the indicated genotypes. GAPDH was used as loading control. c Representative liver images from 6-week-old animals with the indicated genotypes. d Representative images of liver sections from 6-week-old mice with the indicated genotypes stained with $\mathrm{H} \& \mathrm{E}$ or immunostained for $\mathrm{CC} 3$, Ki-67 and cytokeratin 19 (CK19). Arrowheads point at intact bile ducts in periportal areas in floxed mice or necrotic foci observed in the same areas in TAK $1^{\text {LPC-KO }}$ and TAK $1^{\text {LPC-KO }}$ FADD ${ }^{\text {LPC-KO }}$ livers. Arrows denote proliferating bile duct cells in the latter two genotypes. Asterisks indicate necrotic areas in the liver parenchyma only seen in TAK1 $1^{\mathrm{LPC}-\mathrm{KO}}$ FADD ${ }^{\mathrm{LPC}-\mathrm{KO}}$ mice. e Quantification of CC3 and Ki-67 immunostaining shown in D. f qRT-PCR gene expression analysis in liver samples of mice with the indicated genotypes. Graphs show relative mRNA expression normalized to Tbp. The number of mice analyzed $(n)$ is indicated in every graph. All graphs show mean values of the individual data points. $* p<0.05, * * p<0.01$, $* * * p<0.005$. Bars: c $1 \mathrm{~cm} ; \mathbf{d} 100 \mu \mathrm{m}$

Most TAK1 $1^{\text {LPC-KO }}$ mice developed cachexia and died spontaneously prior to 30 weeks of age. The livers of TAK $1{ }^{\text {LPC-KO }}$ mice surviving between $21-39$ weeks exhibited macroscopically visible tumors (Fig. 2a and S2), and histopathological analysis revealed the presence of ceroid/ bile-containing macrophages, marked portal inflammation and bile duct necrosis. Moreover, all TAK1 $1^{\mathrm{LPC}-\mathrm{KO}}$ mice displayed many dysplastic nodules with diameter up to 5 $\mathrm{mm}$ and some well-differentiated HCCs characterized by peritumoral fibrosis, as illustrated by Masson's trichrome staining (Fig. 2b-d). The tumor burden of TAK $1^{\text {LPC-KO }}$ mice was also evident by the increased liver-to-body weight (LW/BW) ratio (Fig. 2e). Strikingly, TAK1 $1^{\text {LPC-KO }}$ FADD $^{\text {LPC-KO }}$ mice did not show spontaneous mortality and lacked dysplastic lesions or HCC when aged up to 1 year (Fig. 2a-e, S2 and S3), although most of these mice exhibited liver fibrosis and as high bilirubinemia as TAK $1{ }^{\text {LPC-KO }}$ mice (Fig. 2b, f). These results show that FADD-dependent hepatocyte apoptosis is essential for driving hepatocarcinogenesis in TAK $1{ }^{\mathrm{LPC}-\mathrm{KO}}$ mice.

\section{RIPK1-dependent necroptosis drives biliary damage in TAK1 ${ }^{\text {LPC-KO }}$ mice}

To examine the contribution of necroptosis in chronic liver damage, we generated TAK1 ${ }^{\mathrm{LPC}-\mathrm{KO}} \operatorname{Ripk}^{-1-}$ mice. As shown previously [8], systemic RIPK3 deficiency reduced biliary damage in 6-week-old mice but did not prevent hepatocyte apoptosis and the strong regenerative response elicited from it (Fig. 1b and S4A-B). Moreover, 28-weekold TAK1 $1^{\mathrm{LPC}-\mathrm{KO}}$ Ripk $^{-1-}$ mice exhibited multiple dysplastic nodules (Fig. S4C-D).

Next, we addressed the role of RIPK1 by generating mice lacking both TAK1 and RIPK1 in LPCs. These mice appeared healthy and showed no signs of cholestatic disease. Six-week-old TAK1 ${ }^{\text {LPC-KO }}$ RIPK1 ${ }^{\text {LPC-KO }}$ mice showed no significant reduction in ALT levels compared to TAK $1^{\mathrm{LPC}-\mathrm{KO}}$ mice. In stark contrast, total bilirubin and ALP were reduced to nearly normal levels (Fig. 3a and S1A). Accordingly, TAK1 $1^{\mathrm{LPC}-\mathrm{KO}}$ RIPK1 ${ }^{\mathrm{LPC}-\mathrm{KO}}$ mice showed only slightly reduced number of $\mathrm{CC}^{+}$apoptotic hepatocytes compared to TAK $1^{\text {LPC-KO }}$ mice, but did not exhibit a substantial number of dying or $\mathrm{Ki}-67^{+}$cholangiocytes or the characteristic periportal necrotic lesions seen in TAK1 $1^{\text {LPC-KO }}$ mice (Fig. 3b, d, e). The livers of 6-week-old TAK1 ${ }^{\text {LPC-KO }}$ RIPK1 ${ }^{\text {LPC-KO }}$ mice appeared macroscopically normal, while histological analysis revealed a moderate decrease in hepatocyte proliferation and ductular reaction (Fig. 3c-f). Furthermore, these mice showed only slight reduction in hepatitis and fibrosis indicators (Fig. 3f and S1B, C). Additional LPC-specific deletion of FADD normalized serum ALT levels and fully prevented inflammation, fibrosis and the remaining histopathological features of TAK $1^{\text {LPC-KO }}$ RIPK $1^{\text {LPC-KO }}$ mice (Fig. 3 and S1), suggesting that RIPK1-independent FADD/Caspase-8 signaling mediates apoptosis in TAK1-deficient hepatocytes.

To address the role of RIPK1 kinase activity, we generated TAK1 ${ }^{\mathrm{LPC}-\mathrm{KO}}$ Ripk $^{\mathrm{D} 138 \mathrm{~N} / \mathrm{D} 138 \mathrm{~N}}$ mice, which express a kinase inactive RIPK1 mutant. Similar to complete lack of RIPK1, RIPK $1^{\text {D138N }}$ expression moderately decreased ALT levels but completely abrogated the bilirubinemia of TAK1 ${ }^{\text {LPC-KO }}$ mice (Fig. 3a). The livers of 6-week-old TAK1 ${ }^{\text {LPC-KO }}$ Ripkl $^{\text {D138N/D138N }}$ mice appeared macroscopically normal, lacked periportal necrotic lesions and showed reduced numbers of $\mathrm{CC}^{+}$apoptotic hepatocytes compared to TAK $1^{\mathrm{LPC}-\mathrm{KO}}$ mice. Accordingly, a modest decrease in most markers of hepatocyte proliferation, inflammation, fibrosis and ductular reaction was observed, although all these markers were still significantly higher than in control mice (Fig. 3b-f and S1). Taken together, these data suggest that the hepatocellular damage in TAK $1^{\text {LPC-KO }}$ mice is due to FADD/Caspase-8-mediated apoptosis, which is only partly driven by RIPK1 kinase activity and is independent of necroptosis. On the contrary, the biliary damage is dependent on RIPK1/RIPK3-mediated necroptosis.

\section{Unlike hepatocytes, cholangiocytes can undergo necroptosis}

The relevance of hepatocyte necroptosis in liver disease mouse models is debated [12, 21, 22]. Because the Alfp Cre we used induces gene deletion both in hepatocytes and cholangiocytes [19], we compared these two cell types for their ability to undergo necroptosis or apoptosis in vitro. Low passage, not transformed/immortalized, normal mouse cholangiocytes (NMCs) and primary hepatocytes were first treated with TNF and the Smac mimetic (SM) Birinapant, a 
A

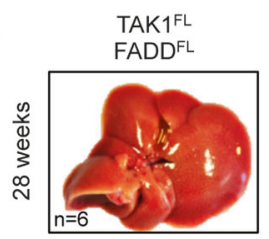

B

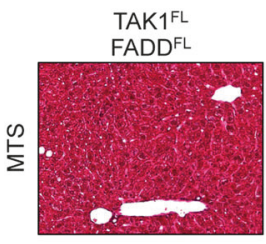

D

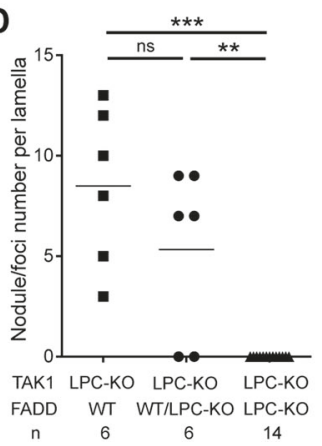

TAK1LPC-KO

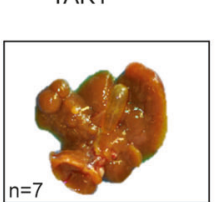

TAK1 1 LPC-KO

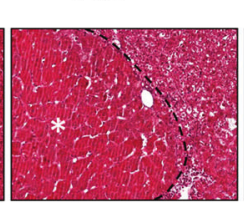

TAK1 1 LPC-KO FADDLPC-KO

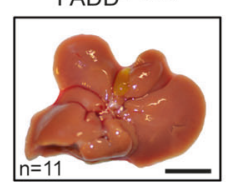

TAK1 1 LPC-KO

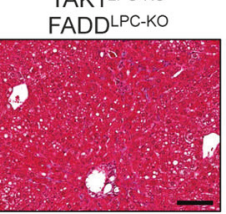

C

$$
\begin{aligned}
& \text { TAK1 }^{\text {LPC-KO }} \text { FADD }^{\text {LPC-KO }}(n=11) \\
& \text { TAK1 }^{\text {LPC-KO }} \text { FADD }^{\text {WT/LPC-KO }}(n=6) \\
& \operatorname{TAK1~}^{\text {LPC-KO }}(>21 w)(n=6)
\end{aligned}
$$

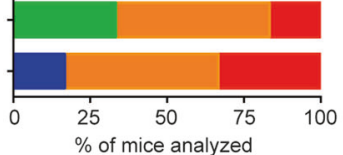

High Grade dysplasia / HCC

$>5$ dysplastic nodules/foci per lamella

$\leq 5$ dysplastic nodules/foci per lamella

No dysplastic nodules/foci
E

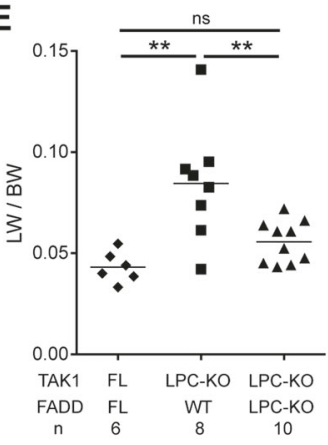

Fig. 2 LPC-specific deletion of FADD prevents hepatocarcinogenesis in TAK1 ${ }^{\mathrm{LPC}-\mathrm{KO}}$ mice. a Representative liver images from 28 -week-old mice with the indicated genotypes. b Representative images of Masson's trichrome stained liver sections from 28 -week-old mice with the indicated genotypes. HCC is outlined and marked with an asterisk. c Histopathological evaluation of hepatocarcinogenesis in samples of 21-to-28-week-old mice. d Quantification of dysplastic nodules/foci

combination that induces RIPK1-dependent cell death [23]. Indeed, TNF/SM induced robust death in both cell types (Fig. 4a). Strikingly, while the pan-Caspase inhibitor zVAD-fmk fully rescued hepatocyte death, it had no effect in NMCs. In contrast, the RIPK1 kinase inhibitor Nec1s inhibited almost completely TNF/SM-induced death in NMCs. Similar results were obtained in the presence of the TAK1 inhibitor 5Z-7-Oxozeaenol used to mimic the LPCspecific TAK1 deficiency (Fig. 4a). Moreover, we tested the susceptibility of hepatocytes and cholangiocytes to TNF and actinomycin D (ActD), a combination inducing RIPK1independent cell death [23] (Fig. 4b). Again, TNF/ActDinduced death was fully prevented by zVAD-fmk in primary hepatocytes but as expected, Nec1s showed no protective effect. In NMCs, while zVAD-fmk or Nec1s treatment alone did not prevent cell death, combined treatment conferred full protection. Accordingly, FADDdeficient primary hepatocytes were resistant to TNF/ActDinduced cell death, whereas RIPK3-deficient hepatocytes were as sensitive as the wildtype ones (Fig. S4E). These results indicate that hepatocytes can exclusively undergo apoptosis, while cholangiocytes can undergo necroptosis when apoptosis is inhibited.
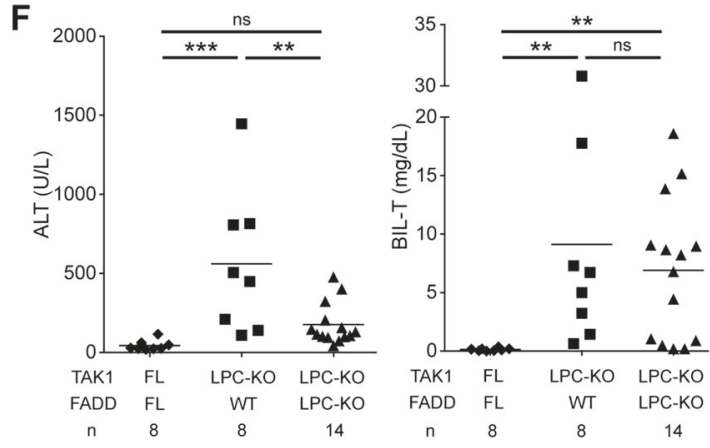

per lamella in liver sections of mice with the indicated genotype. e-f Liver:body weight (LW/BW) ratio (e) and serum ALT and total Bilirubin levels in 28-week-old mice with the indicated genotypes (f). The number of mice analyzed $(n)$ is indicated in every graph. All graphs show mean values of the individual data points. ${ }^{*} p<0.05$, $* * p<0.01, * * * p<0.005$. Bars: a $1 \mathrm{~cm} ; \mathbf{b} 100 \mu \mathrm{m}$

To investigate the reason for this cell type-specific differences, we compared the protein levels of key apoptosisand necroptosis-associated molecules (Fig. 4c). The lack of RIPK3 expression in hepatocytes compared to its robust expression in NMCs was the most prominent difference observed. Interestingly, hepatocytes appear to express high levels of FADD compared to NMCs. Since the expression of all other critical necroptosis-mediating molecules (MLKL, RIPK1, ZBP1) is similar between the two cell types, the absence of RIPK3 is likely responsible for hepatocyte resistance to necroptosis.

Supporting these data, immunostaining with a highly specific anti-RIPK3 antibody [24] showed that RIPK3 was predominantly expressed in non-LPCs, while some nonspecific staining was observed in hepatocytes undergoing apoptosis (Fig. 4d). Immunohistochemistry on serial liver sections showed that RIPK3-expressing cells represented mainly $\mathrm{F} 4 / 80^{+}$macrophages and other $\mathrm{CD} 45^{+}$leukocytes (Fig. S5). Interestingly, bile ducts in $\mathrm{TAK} 1^{\mathrm{LPC}-\mathrm{KO}}$ and TAK $1^{\text {LPC-KO }}$ FADD ${ }^{\text {LPC-KO }}$ mice often expressed high levels of RIPK3, although this was rarely observed in wildtype mice (Fig. 4d and S5). Moreover, immunohistochemical detection of phospho-RIPK3, a marker of activated 

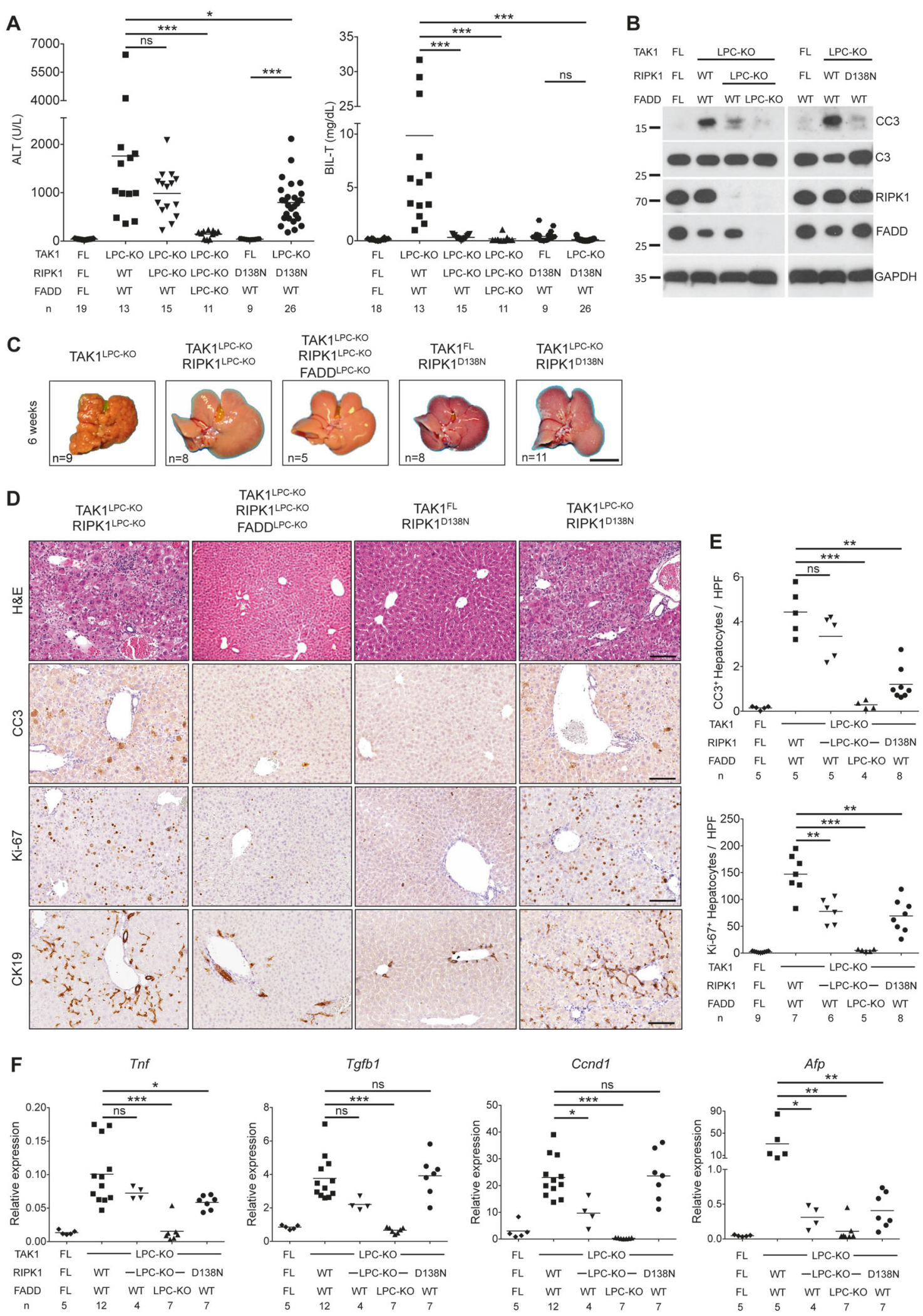

necroptosis, was not observed in hepatocytes but mostly in liver leukocytes and to a lower extent in cholangiocytes of TAK $1^{\text {LPC-KO }}$ and TAK $1^{\text {LPC-KO }}$ FADD ${ }^{\text {LPC-KO }}$ mice (Fig. 4e).
The low frequency of necroptotic cholangiocytes detected is somewhat expected as dying cells are rapidly shed into the bile duct lumen. Altogether, these results are in agreement 
Fig. 3 RIPK1 kinase activity drives cholestasis but is largely dispensable for hepatocellular damage in TAK $1^{\mathrm{LPC}-\mathrm{KO}}$ mice. a Serum levels of ALT and total Bilirubin in 6-week-old mice with the indicated genotypes. b Immunoblot analysis of whole liver lysates from 6week-old mice with the indicated genotypes. GAPDH was used as loading control. c Representative liver images from 6-week-old animals with the indicated genotypes. d Representative images of liver sections from 6-week-old mice with the indicated genotypes stained with H\&E or immunostained for CC3, Ki-67 and CK19. e Quantification of $\mathrm{CC} 3$ and Ki-67 immunostaining shown in d. f qRT-PCR gene expression analysis in liver samples of mice with the indicated genotypes. Graphs show relative mRNA expression normalized to Tbp. The number of mice analyzed $(n)$ is indicated in every graph. All graphs show mean values of the individual data points. $* p<0.05$, $* * p<0.01, * * * p<0.005$. Bars: c $1 \mathrm{~cm} ; \mathbf{d} 100 \mu \mathrm{m}$

with previous studies reporting that RIPK3-dependent necroptosis does not contribute to hepatocellular injury [7, 9, 10, 24-26], while they support a role for necroptosis in biliary injury [27].

\section{RIPK1 regulates HCC development in TAK1 $1^{\text {LPC-KO }}$ mice}

To assess the role of RIPK1 scaffolding properties and kinase activity in hepatocarcinogenesis in TAK $1^{\mathrm{LPC}-\mathrm{KO}}$ mice, we followed mice up to 52 weeks of age. In contrast to TAK $1^{\text {LPC-KO }}$ mice, both TAK $1^{\text {LPC-KO }}$ RIPK $1^{\text {LPC-KO }}$ and TAK1 ${ }^{\text {LPC-KO }}$ Ripk1 $^{\text {D138N/D138N }}$ mice did not die spontaneously, had normal bilirubin levels, and showed moderately reduced ALT levels at 28 weeks of age (Fig. 5a). At this age, the liver of these mice did exhibit aberrant architecture but almost no macroscopically visible tumors bigger than $2 \mathrm{~mm}$ in diameter were present (Fig. 5b and S2). Histological analysis revealed that the majority of the examined livers had many but predominantly small clear cell foci/nodules and no high-grade dysplastic nodules or HCC were identified (Fig. 5c-e). Accordingly, both mouse strains had a LW/BW ratio similar to control mice and significantly lower than TAK $1^{\text {LPC-KO }}$ mice (Fig. 5f). Upon ageing to 1 year, TAK $1^{\text {LPC-KO }}$ RIPK $1^{\text {LPC-KO }}$ and TAK $1^{\text {LPC-KO }}$ Ripk $1^{\text {D138N/D138N }}$ mice eventually developed liver tumors with premalignant or HCC features, although there was a clear tendency for delayed hepatocarcinogenesis in TAK $1^{\mathrm{LPC}-\mathrm{KO}}$ Ripk1 $1^{\mathrm{D} 138 \mathrm{~N} / \mathrm{D} 138 \mathrm{~N}}$ mice (Fig. S3). Finally, no tumors or dysplastic lesions were observed in TAK $1^{\text {LPC-KO }}$ RIPK $1^{\text {LPC-KO }}$ FADD ${ }^{\mathrm{LPC}-\mathrm{KO}}$ mice (Fig. 5, S2 and S3). Therefore, lack of RIPK1 or inhibition of its kinase activity significantly ameliorated early hepatocarcinogenesis but could not prevent HCC development in aged TAK $1^{\text {LPC-KO }}$ mice.

\section{NEMO mediates biliary damage but is dispensable for liver tumorigenesis in TAK $1^{\text {LPC-KO }}$ mice}

TAK1 acts sequentially with the IKK complex to promote cell survival both by activating $\mathrm{NF}-\kappa \mathrm{B}$ signaling and through NF-кB-independent mechanisms [3, 13, 14]. Surprisingly, a former study showed that lack of NEMO in LPCs prevented cholestasis and hepatocarcinogenesis in 21week-old $\mathrm{TAK} 1^{\mathrm{LPC}-\mathrm{KO}}$ mice, although it did not reduce hepatocyte death [18]. We therefore decided to reinvestigate these intriguing findings by generating TAK $1^{\text {LPC-KO }}$ NEMO $^{\text {LPC-KO }}$ mice.

Our analysis confirmed that TAK $1^{\text {LPC-KO }}$ NEMO $^{\text {LPC-KO }}$ mice did not develop jaundice or spontaneous lethality. Accordingly, at 6 and 12 weeks of age, total bilirubin in most of TAK $1^{\text {LPC-KO }}$ NEMO ${ }^{\text {LPC-KO }}$ mice was similar to wildtype controls, while ALT levels were comparable to the single knockout mice (Fig. 6a, b). However, in contrast to the study by Bettermann et al. [18], our histopathological evaluation revealed that 12-week-old TAK $1^{\text {LPC-KO }}$ NEMO $^{\text {LPC-KO }}$ mice already exhibited many dysplastic foci and nodules resembling more the phenotype of TAK $1^{\text {LPC-KO }}$ rather than NEMO ${ }^{\text {LPC-KO }}$ mice (Fig. 6c). Livers from 28- and 52-week-old mice had macroscopically visible tumors and almost all exhibited high-grade dysplastic nodules or HCC (Fig. 6d-f), stages that could be detected only in 52-week-old NEMO ${ }^{\text {LPC-KO }}$ mice $[4,7]$. Interestingly, most one-year-old TAK $1^{\text {LPC-KO }}$ NEMO $^{\text {LPC-KO }}$ mice did eventually develop high bilirubinemia and had a higher LW/BW ratio indicative of increased tumor load (Fig. 6b, g). These results suggest that NEMO promotes biliary damage during the early stages of disease development but its absence only marginally delays early hepatocarcinogenesis in TAK $1^{\mathrm{LPC}-\mathrm{KO}}$ mice.

\section{TNFR1/DR signaling triggers biliary but not hepatocellular damage in TAK $1^{\mathrm{LPC}-\mathrm{KO}}$ mice}

TNFR1 signaling inhibition was previously shown to ameliorate liver damage, hepatitis and fibrosis in TAK $1^{\Delta \text { hep }}$ mice, which do not present with biliary damage [20]. To address the role of DR signaling in mice with hepatobiliary injury, we first generated TAK $1^{\text {LPC-KO }}$ mice that also lack 3 death receptors (3DR; TNFR1, Fas and TRAILR) in LPCs [6]. Strikingly, TAK $1^{\text {LPC-KO }} 3 \mathrm{DR}^{\mathrm{LPC}-\mathrm{KO}}$ mice had nearly normal bilirubin and ALP levels but not significantly reduced ALT levels compared to TAK $1^{\mathrm{LPC}-\mathrm{KO}}$ mice (Fig. 7a and $\mathrm{S} 1 \mathrm{~A})$. By generating TAK $1^{\mathrm{LPC}-\mathrm{KO}}$ mice lacking only one or two DRs, we found that TAK $1^{\text {LPC-KO }}$ TNFR $1^{\text {LPC-KO }}$ mice were almost equally protected from biliary damage as TAK $1^{\text {LPC-KO }} 3 \mathrm{DR}^{\mathrm{LPC}-\mathrm{KO}}$ mice (Fig. 7a), suggesting that TNFR1 signaling is the main driver of cholangiocyte death. Similar to genetic manipulations that prevented development of cholestasis (Fig. 3), 6-week-old TAK1 ${ }^{\text {LPC-KO }}$ $3 \mathrm{DR}^{\mathrm{LPC}-\mathrm{KO}}$ mice still showed elevated numbers of $\mathrm{CC}^{+}$ hepatocytes, fibrosis, hepatocytes proliferation and ductular reaction (Fig. 7b, c and S1B-C). 


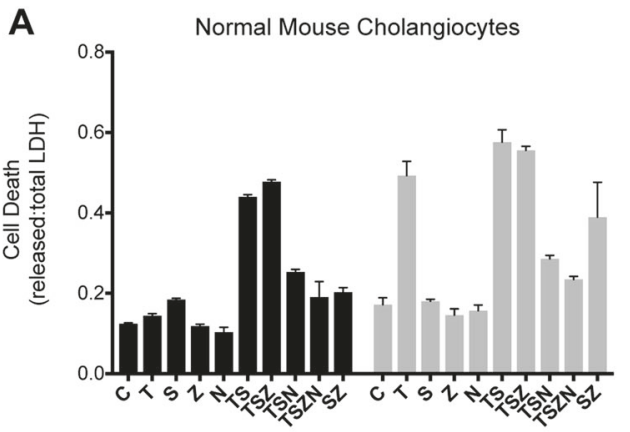

24h incubation

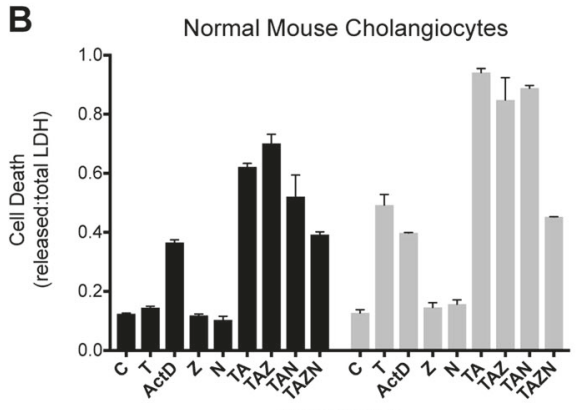

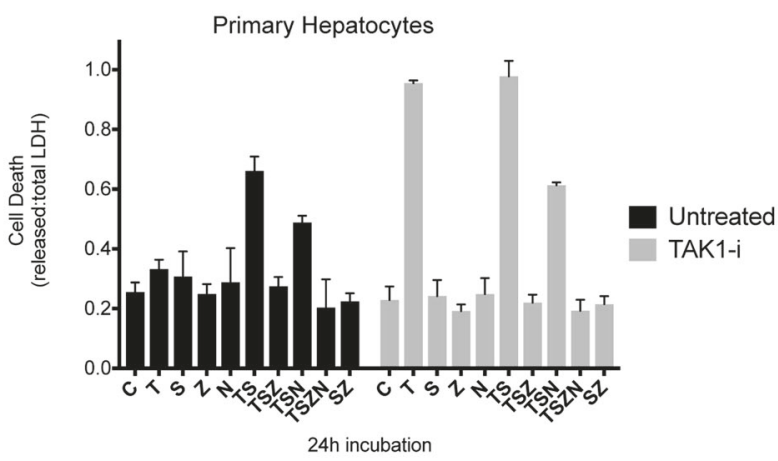

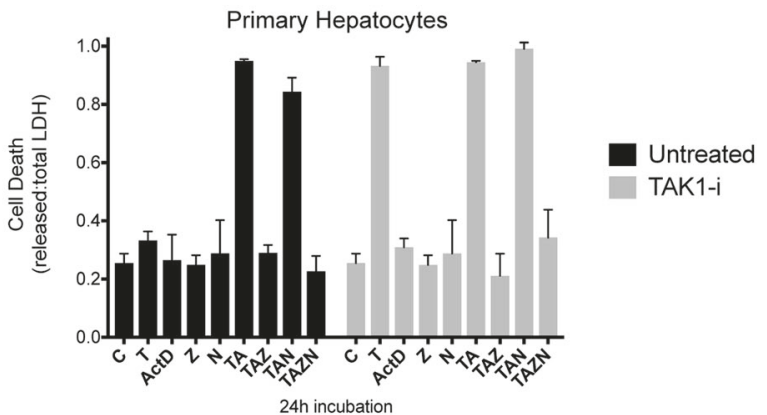

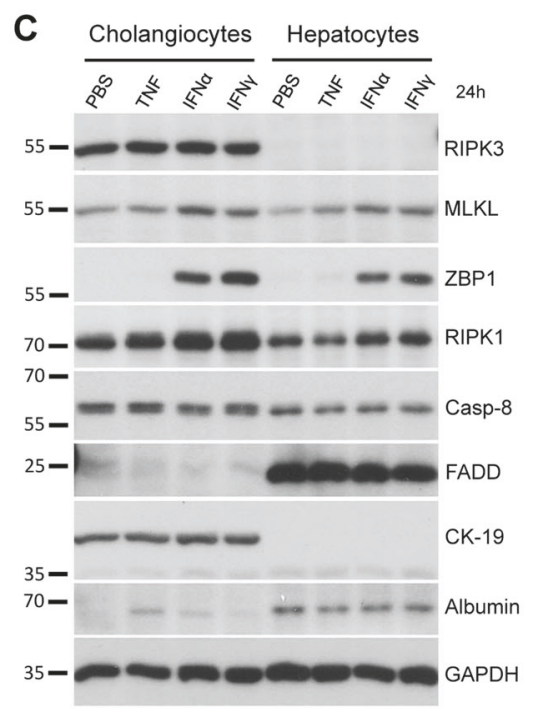
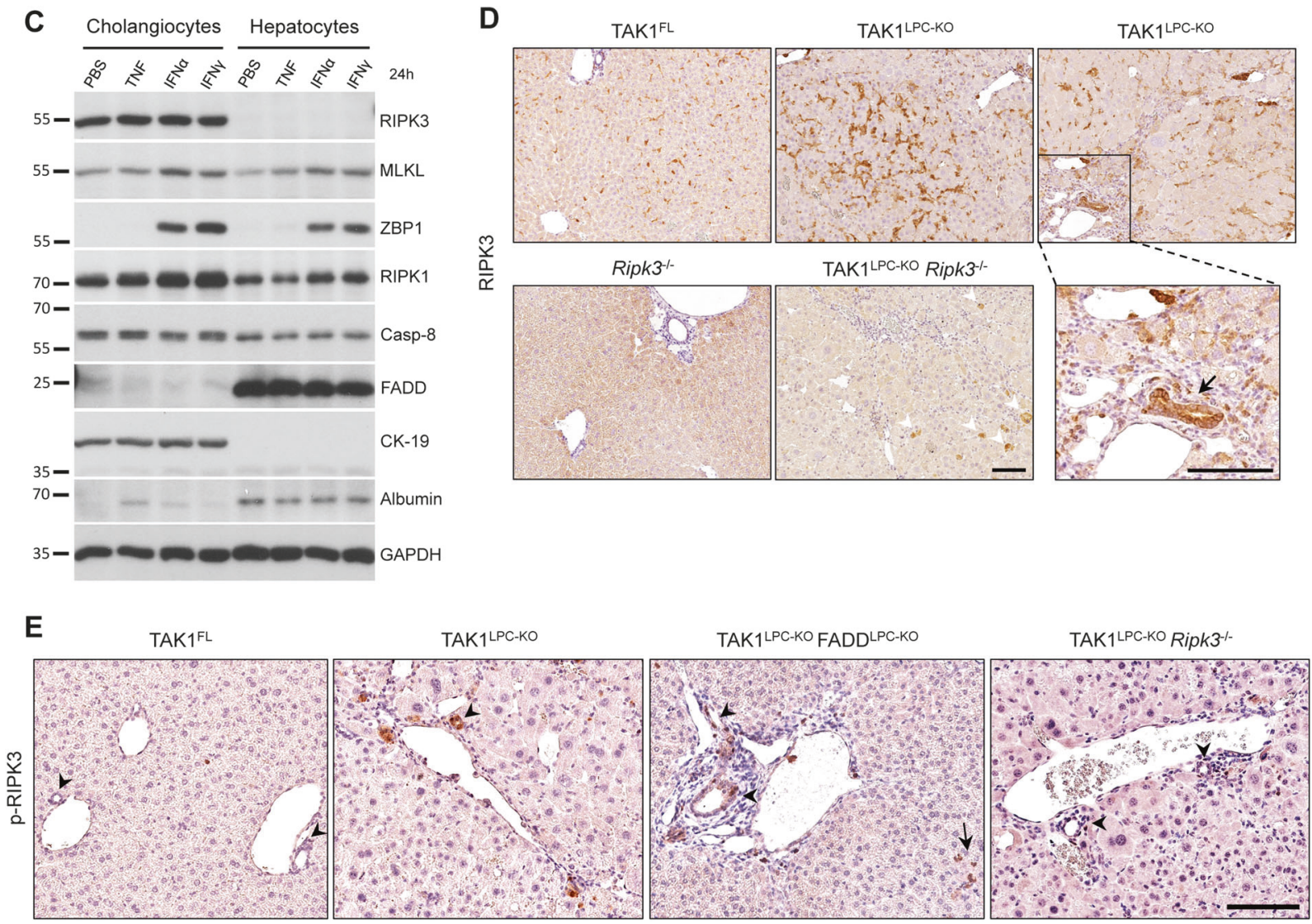

TAK1 $1^{\text {LPC-KO }} 3 \mathrm{DR}^{\mathrm{LPC}-\mathrm{KO}}$ mice were aged to 28 weeks without showing spontaneous lethality. Unlike TAK1 $1^{\text {LPC-KO }}$ mice, only four out $16 \mathrm{TAK} 1^{\mathrm{LPC}-\mathrm{KO}} 3 \mathrm{DR}^{\mathrm{LPC}-\mathrm{KO}}$ mice developed liver tumors larger than $2 \mathrm{~mm}$, athough all livers displayed aberrant architecture (Fig. 7d). Accordingly, histological analysis revealed the presence of multiple 
Fig. 4 Cholangiocytes, but not hepatocytes, can undergo necroptosis. a, b Cell death expressed as released vs. total LDH ratio in normal mouse cholangiocytes and primary hepatocytes treated with TNF/ Smac mimetic (a) or TNF/ActinomycinD (b) together with indicated inhibitors for $24 \mathrm{~h}$ (DMSO, C; T, TNF; S, Smac mimetic; Z, zVADfmk; N, Nec1s; A, Actinomycin D). Cells additionally pre-treated with 5Z-7-Oxozeaenol (TAK1-i) are shown in grey bars. The results of one representative experiment $(n=3)$ are shown. Error bars represent SD of the technical triplicate. c Immunoblot analysis of apoptosis- and necroptosis-associated molecules in lysates from normal mouse cholangiocytes and primary hepatocytes treated with vehicle (PBS), TNF, Interferon $\alpha$ (IFN $\alpha)$ or IFN $\gamma$ for $24 \mathrm{~h}$. GAPDH was used as loading control. d Immunostaining for RIPK3 in liver sections from 6-weekold mice with the indicated genotypes. Boxed area on the right is shown magnified and the arrow points at high RIPK3-expressing cholangiocytes observed in TAK $1^{\mathrm{LPC}-\mathrm{KO}}$ mice. Note the background RIPK3 staining in apoptotic hepatocytes (arrowheads) of TAK $1^{\text {LPC-KO }}$ Ripk $3^{-I-}$ mice. e Immunostaining for phospho-RIPK3 in liver sections from 6-week-old mice with the indicated genotypes. Note the occasional detection of pRIPK $^{+}$cholangiocytes in bile ducts of TAK1 $1^{\text {LPC-KO }}$ and TAK1 $1^{\text {LPC-KO }}$ FADD ${ }^{\text {LPC-KO }}$ mice. Bars: (d, e) $100 \mu \mathrm{m}$

dysplastic foci/nodules but not HCC in TAK $1^{\text {LPC-KO }}$ $3 \mathrm{DR}^{\mathrm{LPC}-\mathrm{KO}}$ mice, while even TNFR1 deficiency alone conferred significant delay in hepatocarcinogenesis of TAK $1^{\text {LPC-KO }}$ mice (Fig. 7e, f). The reduced tumor burden was also reflected in the decreased $\mathrm{LW} / \mathrm{BW}$ ratio compared to TAK $1^{\mathrm{LPC}-\mathrm{KO}}$ mice (Fig. $7 \mathrm{~g}$ ). These results suggest that the spontaneous death of TAK1-deficient cholangiocytes observed in vivo is triggered predominantly by TNFR1 activation, while apoptosis of TAK1-deficient hepatocytes is 3DR-independent.

\section{Discussion}

Chronically elevated hepatocyte apoptosis has been recognized as a prominent driver of liver disease pathogenesis [4-11]. In contrast, the role of necroptosis in acute and chronic liver injury models remains debatable due to nonconclusive or contradicting data [12]. Here, we show that in TAK $1^{\text {LPC-KO }}$ mice both apoptotic and necroptotic cell death pathways with distinct molecular requirements contribute to liver pathology, albeit in different cell types (Fig. 8). TAK1deficient hepatocytes are prone to FADD/Caspase-8-mediated apoptosis, and this pathway is independent of TNFR1, FAS and TRAILR (3DR) and only partially depends on RIPK1 kinase activity. On the contrary, TAK1-deficient bile epithelial cells are susceptible to RIPK1/RIPK3-dependent necroptosis triggered by DRs and primarily TNFR1.

Hepatocytes are considered refractory to necroptosis due to very low RIPK3 expression and this study [24]. Nevertheless, upregulation of RIPK3 expression in the liver has been reported in liver injury models of alcoholic and nonalcoholic steatohepatitis [21, 22]. Our immunostaining data support previous studies showing that in healthy liver,
RIPK3 is mainly expressed in resident immune cells, such as Kupffer cells [24, 28]. In chronically injured liver of TAK $1^{\text {LPC-KO }}$ mice, RIPK3 expression was higher but this reflected a strong inflammatory cell infiltration and increased expression in cholangiocytes rather than in hepatocytes. Accordingly, phospho-RIPK3 immunoreactivity was observed mainly in immune cells and a small fraction of cholangiocytes but not in hepatocytes.

RIPK1 kinase activity is dispensable for proinflammatory and prosurvival signaling but it promotes both apoptosis and necroptosis [3]. The in vivo relevance of this pro-apoptotic function in hepatocytes was recently exemplified in $\mathrm{NEMO}^{\mathrm{LPC}-\mathrm{KO}}$ mice or mice treated with TNF and the IKK1/2 inhibitor TPCA-1 [7, 15]. The present study illustrates the existence of a RIPK1 kinasedependent necroptotic pathway that is specifically activated in cholangiocytes and may be relevant for biliary disease. In line with the pro-necroptotic role of RIPK1's scaffolding properties [29], necroptosis was also prevented when RIPK1 was absent from TAK1-deficient cholangiocytes. In contrast, lack of RIPK1 from TAK1-, NEMO- or IKK1/2-deficient hepatocytes did not significantly reduce hepatocellular damage and this study $[7,9]$. In NEMO ${ }^{\text {LPC-KO }}$ mice, this was due to activation of an alternative, TRADD-mediated apoptotic pathway [7], and a recent study confirmed that TRADD-dependent apoptosis is operating in several embryonic tissues of RIPK1-deficient mice [30]. Furthermore, expression of kinase-inactive RIPK1 in TAK1-deficient hepatocytes conferred only moderate protection from apoptosis, suggesting that RIPK1 kinase-independent pathways are also involved. These could include TRADD-dependent apoptosis, but also death induced by TGF $\beta / \mathrm{Smad}$ activation or inhibition of autophagy, which have been reported in TAK1-deficient hepatocytes [31-33]. Whichever of these alternative pathways is activated, it should converge to FADD/Caspase-8 activation, as hepatocyte apoptosis was fully rescued in TAK $1^{\text {LPC-KO }}$ RIPK $1^{\text {LPC-KO }}$ FADD ${ }^{\text {LPC-KO }}$ mice.

Our study confirmed the previously reported role of NEMO in driving biliary damage in TAK $1^{\text {LPC-KO }}$ mice [18]. A necroptosis-promoting function of NEMO has been described in mouse embryonic fibroblasts either by acting as scaffold nucleating RIPK1/RIPK3 necrosome formation or by inducing mitochondria permeabilization [34, 35]. It is, however, unclear whether NEMO facilitates cholangiocyte necroptosis or drives biliary damage through other mechanisms, and whether this function is conserved in other RIPK3-competent cells. In contrast, our results did not confirm the reported inhibition of early hepatocarcinogenesis in TAK $1^{\text {LPC-KO }}$ NEMO ${ }^{\text {LPC-KO }}$ mice [18], since highgrade dysplastic nodules or HCC could be identified in the livers of 28-week-old animals. The reason for this 
Fig. 5 RIPK1 promotes early hepatocarcinogenesis in TAK $1^{\text {LPC-KO }}$ mice through its kinase activity. a Serum ALT and total Bilirubin levels in 28week-old mice with the indicated genotypes. $\mathbf{b}$

Representative liver images from 28-week-old mice with the indicated genotypes. c

Representative images of Masson's trichrome stained liver sections from 28-week-old mice with the indicated genotypes. Dysplastic nodules are outlined and marked with an asterisk. d, e Histopathological evaluation of hepatocarcinogenesis (d) and quantification of dysplastic nodules/foci per lamella (e) in liver sections of 28 -week-old mice with the indicated genotype. $\mathbf{f} \mathrm{LW} / \mathrm{BW}$ ratio in 28week-old mice with the indicated genotypes. The number of mice analyzed (n) is indicated in every graph. All graphs show mean values of the individual data points. ${ }^{*} p<0.05$, $* * p<0.01, * * * p<0.005$. Bars:

b $1 \mathrm{~cm} ; \mathbf{c} 100 \mu \mathrm{m}$
A

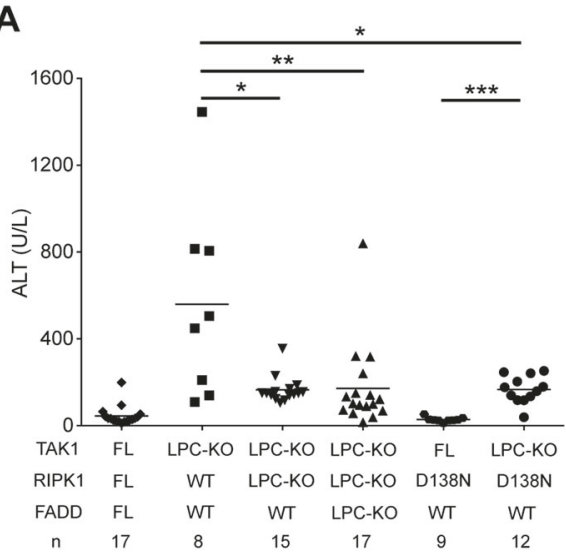

B
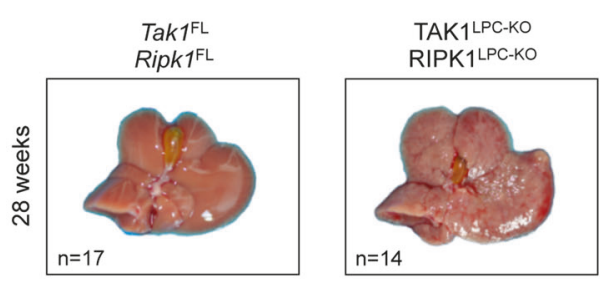

C
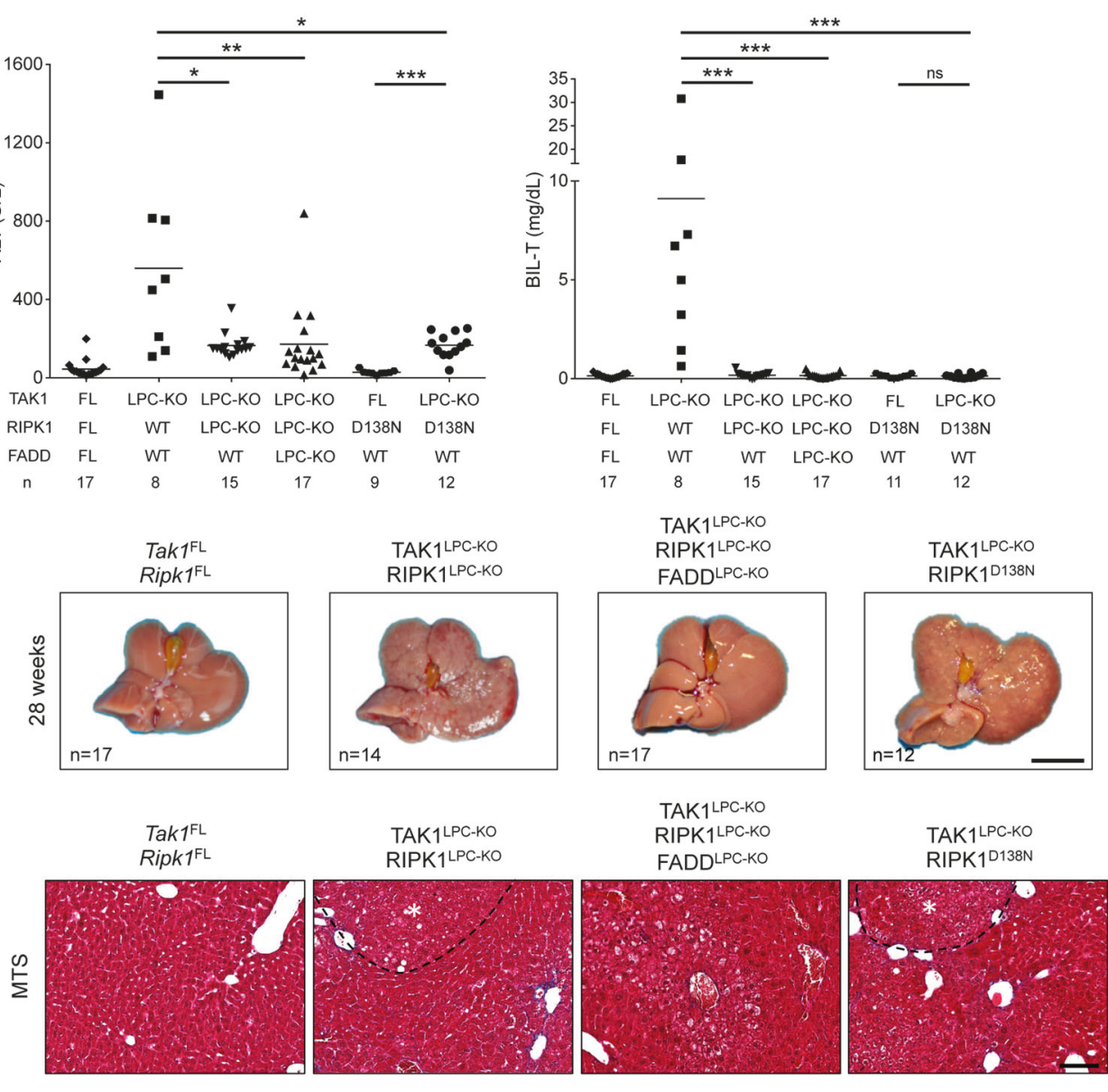

D

$$
\begin{aligned}
& \text { TAK1 }^{\text {LPC-KO RIPK1 }}{ }^{\text {D138N }}(n=7) \\
& \text { TAK1 } 1^{\text {LPC-KO }} \text { RIPK1 }^{\text {LPC-KO FADD }}{ }^{\text {LPC-KO }}(n=7) \\
& \text { TAK1 } 1^{\text {LPC-KO }} \text { RIPKK }^{\text {LPC-KO }}(\mathrm{n}=12) \\
& \operatorname{TAK}^{\text {LPC-KO }}(>21 \mathrm{w})(\mathrm{n}=6)
\end{aligned}
$$
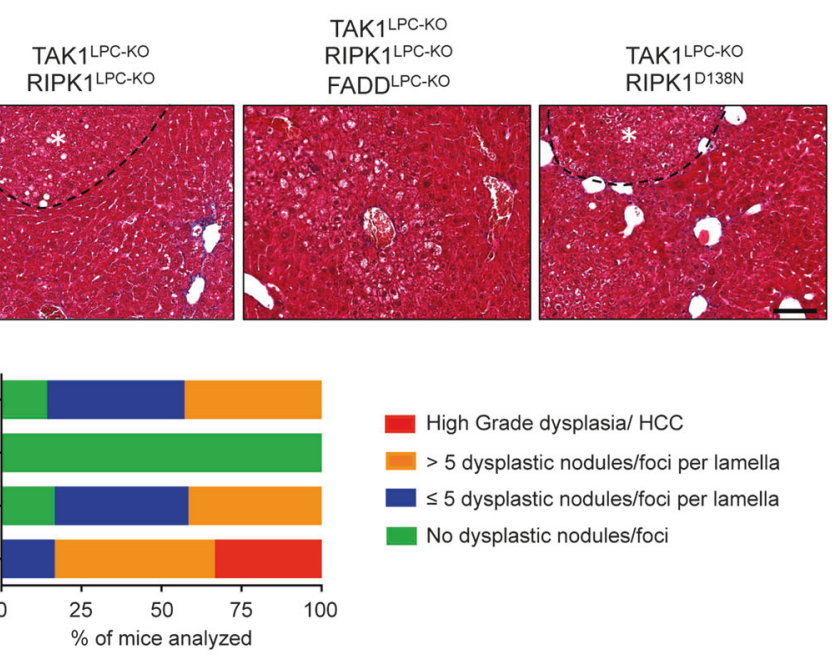

High Grade dysplasia/ HCC

- $>5$ dysplastic nodules/foci per lamella

$\leq 5$ dysplastic nodules/foci per lamella

No dysplastic nodules/foci

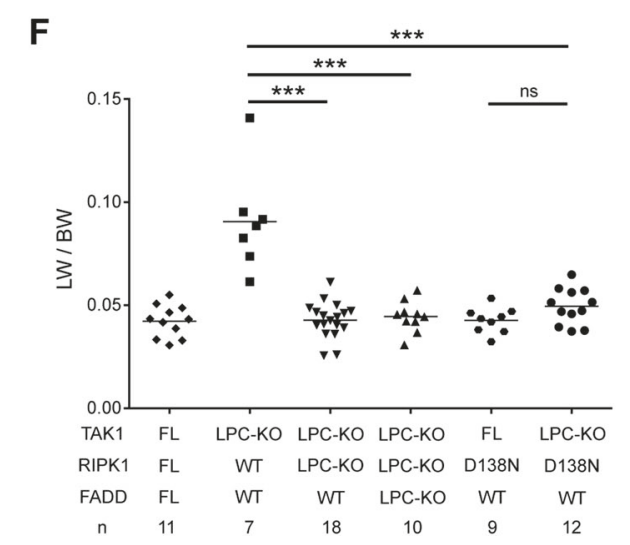

discrepancy is not clear. A possible explanation could be the fact that Bettermann and colleagues used mice bred on a mixed C57/BL6-SV129Ola genetic background, while our mice were bred on pure C57/BL6 background, which could result in different genetic susceptibility to HCC development. 


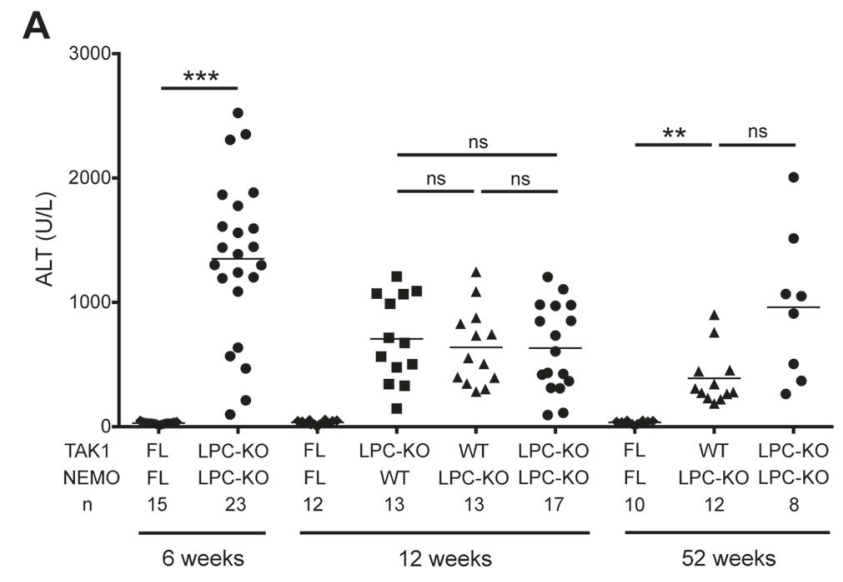

C
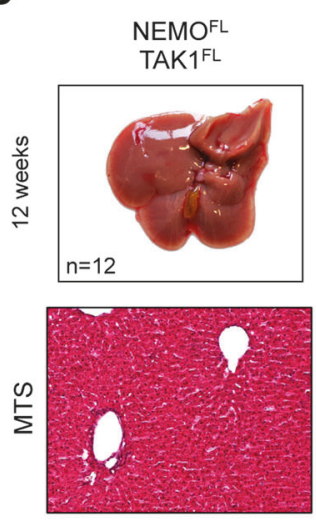

E
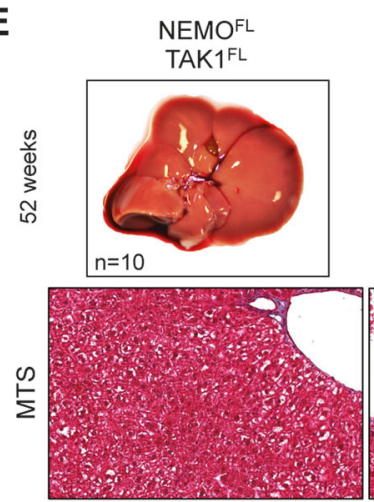

NEMOLPC-KO TAK 1 WT or LPC-KO/WT
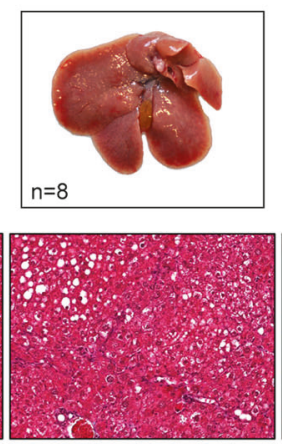
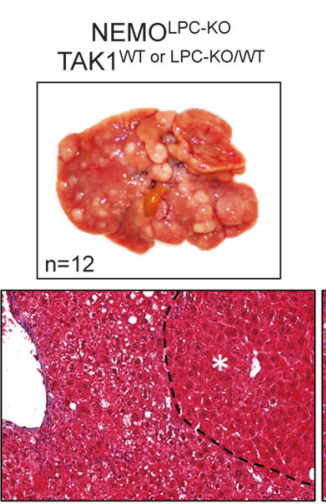

B

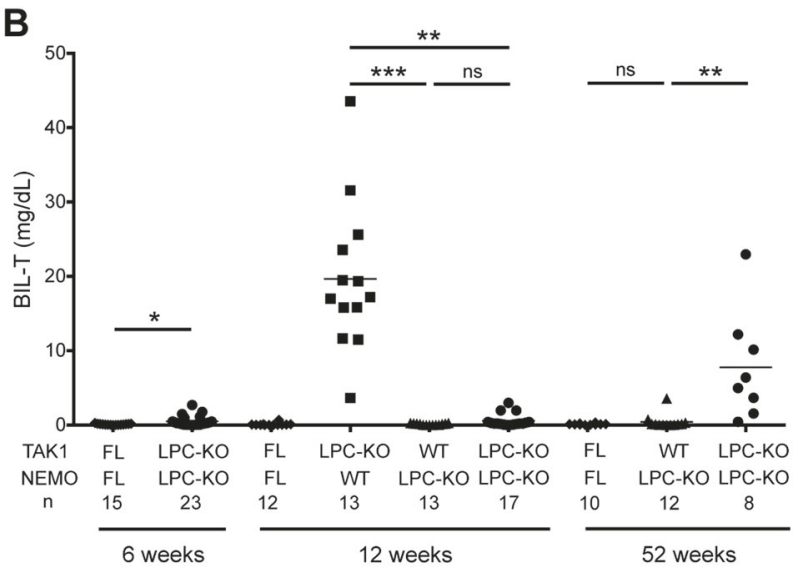

D
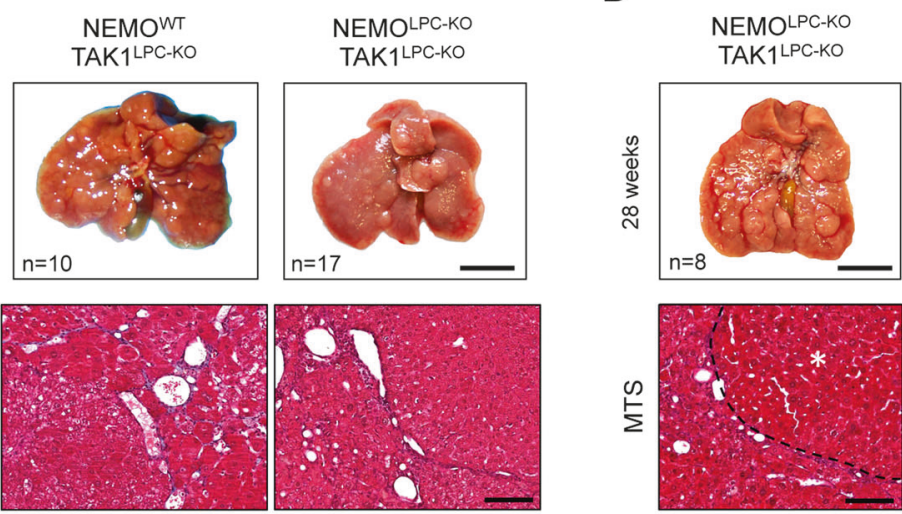
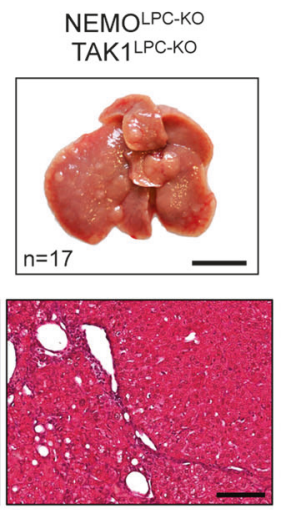
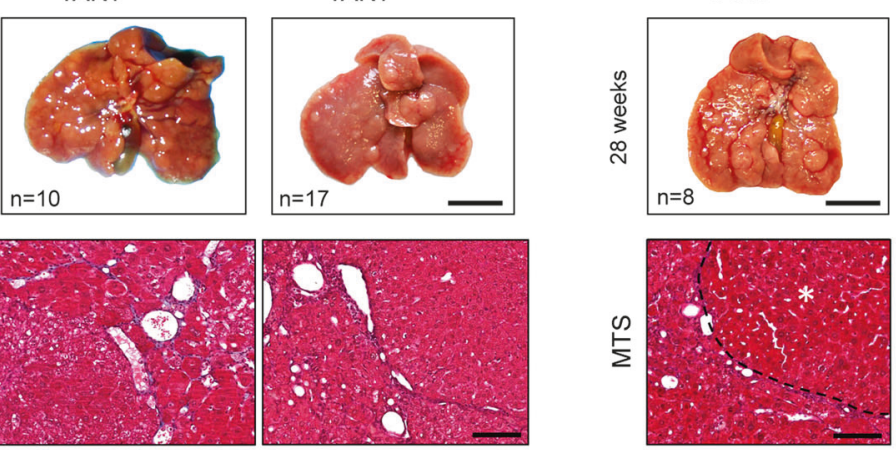
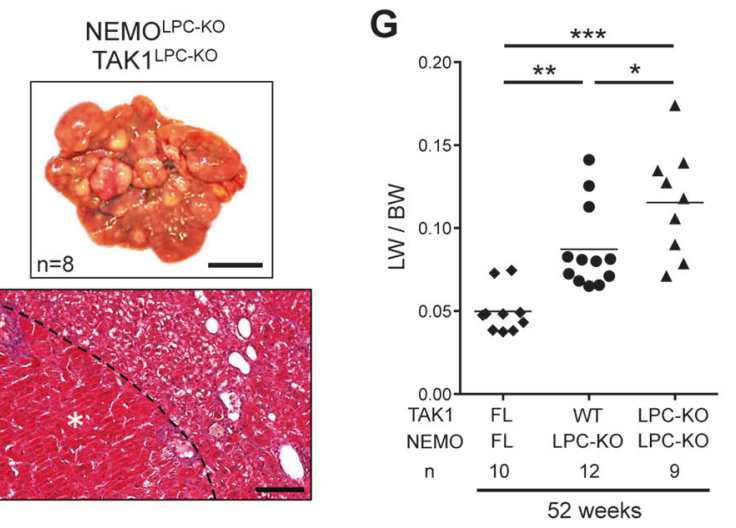

$\mathbf{F}$

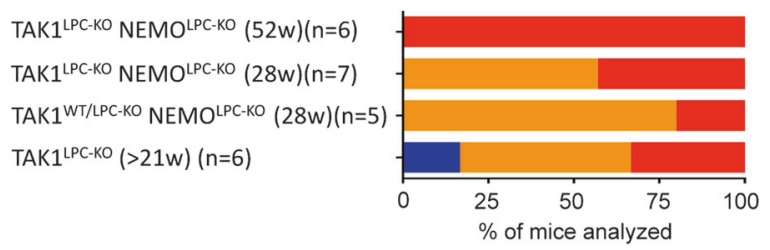

Fig. 6 NEMO deletion strongly prevents biliary damage but leads to only a marginal delay in HCC progression in TAK1 $1^{\mathrm{LPC}-\mathrm{KO}}$ mice. a, b Serum levels of ALT (a) and total Bilirubin (b) in 6-, 12- and 52week-old mice with the indicated genotypes. $\mathbf{c}-\mathbf{e}$ Representative liver photos and images of liver sections stained for Masson's trichrome from 12- (c), 28-(d), and 52-week-old mice (e) with the indicated genotypes. Dysplastic nodules or HCCs are outlined and marked with

an asterisk in $\mathbf{d}$ and e. f Histopathological evaluation of hepatocarcinogenesis in liver samples from mice with the indicated age. $\mathbf{g ~ L W / ~}$ BW ratio in 52-week-old mice with the indicated genotypes. The number of mice analyzed (n) is indicated in every graph. All graphs show mean values of the individual data points. $* p<0.05, * * p<0.01$, $* * * p<0.005$. Bars: c, e upper, $1 \mathrm{~cm}$; lower, $100 \mu \mathrm{m}$ 

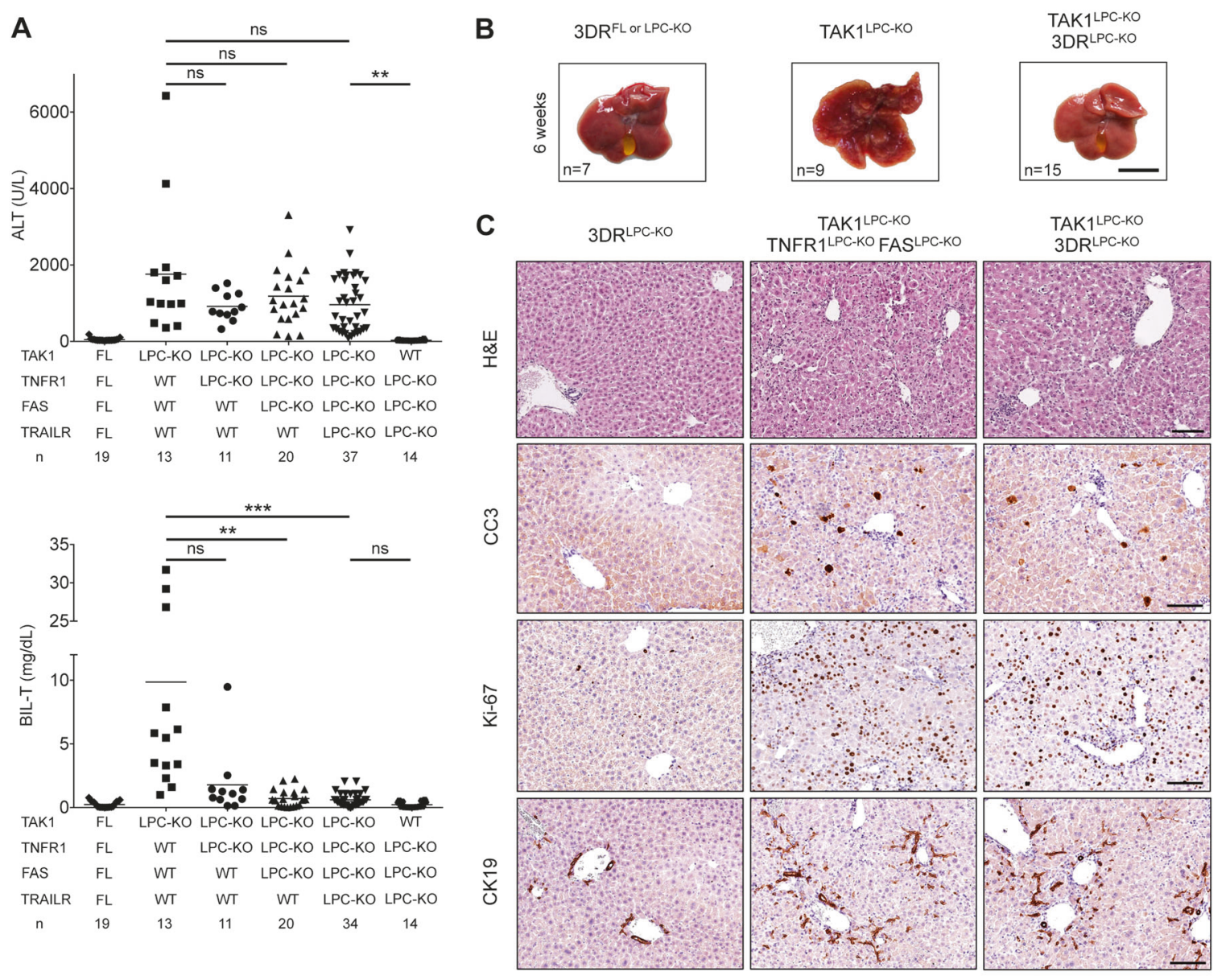

TAK1 1 LPC-KO

D
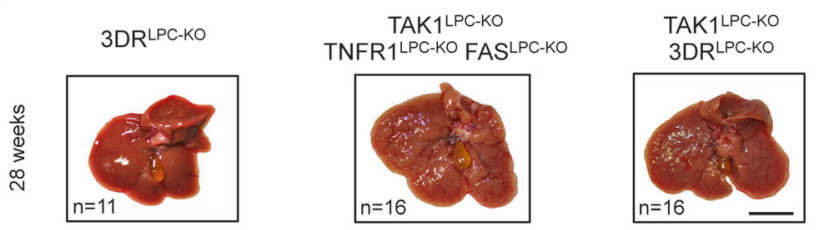

E

$3 \mathrm{DR} \mathrm{LPC}-\mathrm{KO}^{\mathrm{P}}$
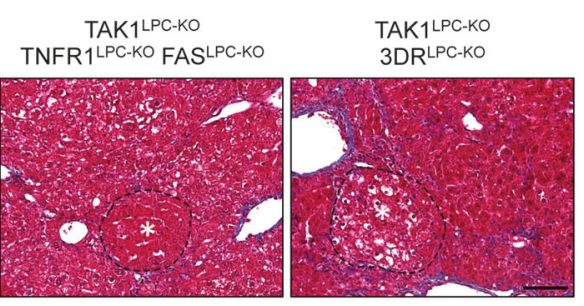

G

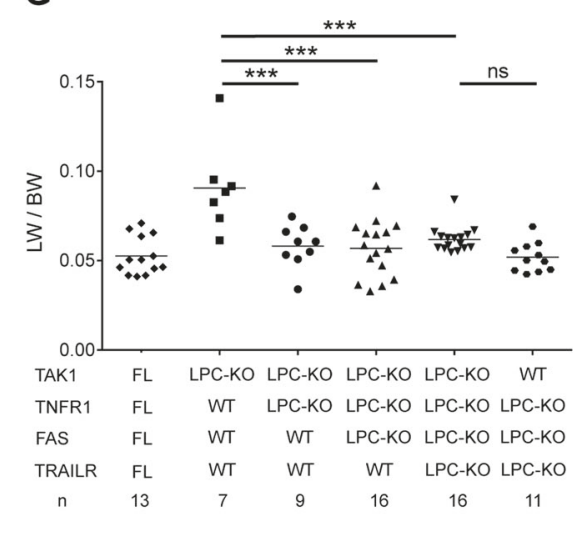
$\mathbf{F}$

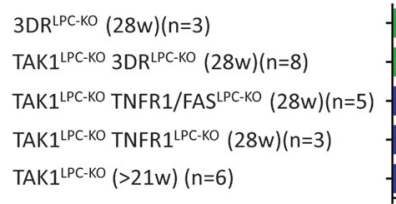

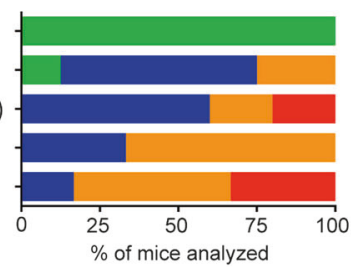

High Grade dysplasia/ HCC

> 5 dysplastic nodules/foci per lamella

$\leq 5$ dysplastic nodules/foci per lamella

No dysplastic nodules/foci

TNFR1 has been partly implicated in triggering hepatocellular damage in TAK $1^{\Delta \mathrm{Hep}}$ mice [20]. However, our data support the involvement of DRs, and particularly of
TNFR1, primarily in inducing cholangiocyte but not hepatocyte death in TAK $1^{\mathrm{LPC}-\mathrm{KO}}$ mice. DRs were also dispensable for spontaneous hepatocyte apoptosis in 
Fig. 7 Death receptor signaling drives biliary but not hepatocellular damage, and significantly delays hepatocarcinogenesis in TAK 1 LPC-KO mice. a Serum levels of ALT and total Bilirubin in 6-week-old mice with the indicated genotypes. b Representative liver images from 6week-old animals with the indicated genotypes. c Representative images of liver sections from 6-week-old mice with the indicated genotypes stained with $\mathrm{H} \& \mathrm{E}$ or immunostained for CC3, Ki-67 and CK19. d, e Representative liver photos (d) and images of liver sections stained for Masson's trichrome (e) from 28-week-old mice with the indicated genotypes. Dysplastic nodules are outlined and marked with an asterisk. f, $\mathbf{g}$ Histopathological evaluation of hepatocarcinogenesis (f) and LW/BW ratio (g) in 28-week-old mice with the indicated genotypes. The number of mice analyzed (n) is indicated in every graph. All graphs show mean values of the individual data points. ${ }^{*} p<$ $0.05, * * p<0.01, * * * p<0.005$. Bars: b, d $1 \mathrm{~cm} ; \mathbf{c}$, e $100 \mu \mathrm{m}$
$\mathrm{NEMO}^{\mathrm{LPC}-\mathrm{KO}}$ and HOIP/LUBAC ${ }^{\Delta \mathrm{Hep}}$ mice $[6,7,36]$. The marginal reduction in ALT levels observed in TAK $1^{\mathrm{LPC}-\mathrm{KO}} 3 \mathrm{DR} \mathrm{R}^{\mathrm{LPC}-\mathrm{KO}}$ mice is probably an indirect effect of preventing bile duct destruction. Conversely, TNFR1 is clearly involved as inducer of hepatocyte apoptosis in RIPK $1^{\text {LPC-KO }}$, NEMO ${ }^{\text {LPC-KO }}$, and TAK $1^{\text {LPC-KO }}$ mice upon acute liver injury models triggered by massive release of proinflammatory cytokines, including TNF, by activated immune cells $[4,7,10,18,25,26,37,38]$. Yet, what triggers spontaneous hepatocyte apoptosis in the aforementioned mice remains unresolved and the role of additional DR-dependent or -independent pathways should be addressed [3].
Fig. 8 Model for the role of cell death in TAK1-deficient LPCs. Proposed model for the contribution of hepatocyte apoptosis and bile epithelial cell necroptosis in the development of chronic liver inflammation, regeneration and hepatocarcinogenesis in TAK $1^{\text {LPC-KO }}$ mice. The observed cholestasis aggravates inflammation possibly by inducing more hepatocyte apoptosis through released bile acid toxicity. Although the role of necroptosis per se is currently unclear, it could regulate the aggressiveness of hepatocarcinogenesis by shaping the inflammatory microenvironment

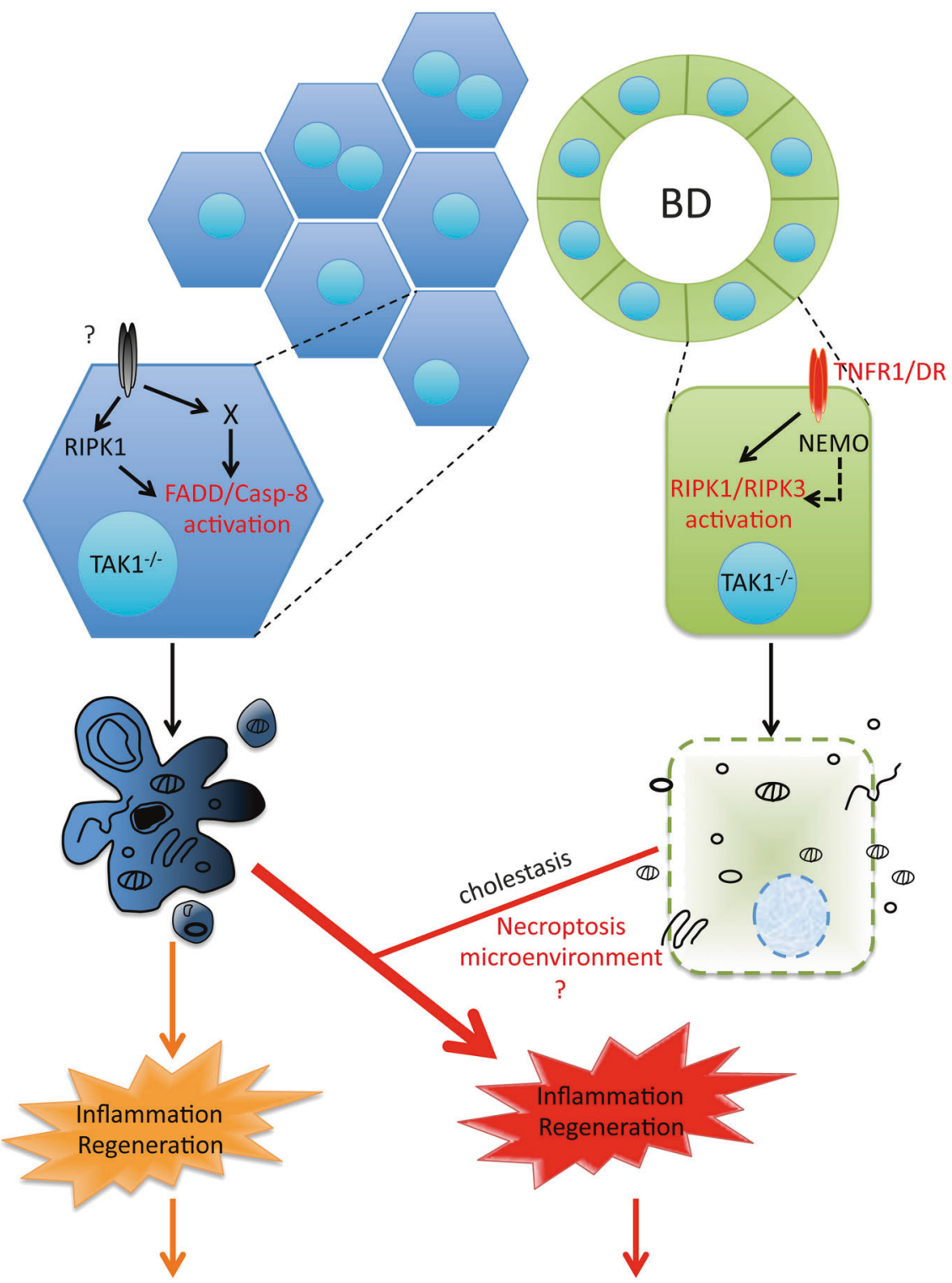

Delayed HCC
Lethality or accelerated HCC 
In agreement with a recent study [11], our results support the decisive role of hepatocyte apoptosis in driving hepatitis and HCC in TAK $1^{\text {LPC-KO }}$ mice. While most TAK $1^{\text {LPC-KO }}$ mice succumb to death due to cholestasis, the survivors develop accelerated HCC (Fig. 8). Inhibition of hepatocyte apoptosis alone could effectively prevent HCC development even in the presence of strong biliary damage. When cholangiocyte death was inhibited without a substantial reduction in hepatocyte apoptosis, lethal cholestasis was prevented but HCC development progressed, albeit slower. This suggests that although not driving hepatocarcinogenesis, biliary damage can act as "rheostat" regulating its aggressiveness. Finally, the strong delay in hepatocarcinogenesis upon expression of kinase-inactive or lack of RIPK1 is also compatible with the proposed cell death-independent role of RIPK1 in promoting DNA damage [11].

In summary, our study in TAK $1^{\mathrm{LPC}-\mathrm{KO}}$ mice demonstrates the ability of hepatocytes to die exclusively through FADD/Caspase-8 mediated apoptosis, whereas cholangiocytes can undergo necroptosis. This striking difference between two cell types, which originate from the same hepatic progenitor cells, is likely due to RIPK3 availability. Intriguingly, a recent study has suggested that hepatocyte necroptosis generates a cytokine microenvironment that promotes the preferential development of intrahepatic cholangiocarcinomas from oncogenically transformed hepatocytes [39]. Considering that mature hepatocytes can be reprogrammed to cholangiocytes following liver injury [40], it remains to be seen whether the reported necroptotically-dying cells are hepatocytes or cholangiocytes. An emerging question is whether RIPK1/RIPK3necroptosis of cholangiocytes is relevant in human cholangiopathies. A recent study reported increased RIPK3 and MLKL levels in primary biliary cirrhosis patients and a partial protection of Ripk $3^{-l-}$ mice from biliary damage induced by bile duct ligation [27], without however addressing the role of RIPK1 kinase activity. Our findings suggest that preventing necroptosis using RIPK1 kinase inhibitors could be effective in treating patients with biliary injury.

\section{Materials and methods}

\section{Animals}

The following mouse lines were used in this study: Alfp-Cre [19], $\operatorname{Takl}^{\mathrm{FL}}$ [41], Nemo ${ }^{\mathrm{FL}}$ [42], Fadd $^{\mathrm{FL}}$ [43], Ripk1 ${ }^{\mathrm{FL}}$ [44], Ripk1 $^{\mathrm{D} 138 \mathrm{~N}}$ [45], Ripk3-/- [46], Tnfrl ${ }^{\mathrm{FL}}$ [47], Fas $^{\mathrm{FL}}$ [48], and Trailr $^{\mathrm{FL}}$ [49]. All alleles were maintained on a C57BL/6 genetic background. Littermates carrying the floxed alleles but not the Alfp-Cre transgene served as controls. Animals were housed in individually ventilated cages in a specific pathogen-free (SPF) mouse facility at the Institute for Genetics, University of Cologne, kept under a $12 \mathrm{hr}$ light cycle, and given a regular chow diet (Harlan diet no. 2918 or Prolab Isopro RMH3000 5P76) and water ad libitum. All animal procedures were conducted in accordance with European, national and institutional guidelines and protocols and were approved by local government authorities (Landesamt für Natur, Umwelt und Verbraucherschutz Nordrhein-Westfalen, Germany).

\section{Biochemical serum analysis}

Alanine aminotransferase (ALT), Alkaline Phosphatase (ALP) and Total Bilirubin (BIL-T) were measured in blood serum using standard assays in a Cobas C111 biochemical analyzer (Roche, Mannheim, Germany).

\section{Histology, Immunohistochemistry (IHC), and quantification}

Tissues were fixed overnight in 4\% paraformaldehyde, embedded in paraffin, and cut into $5 \mu \mathrm{m}$ sections. $\mathrm{H} \& \mathrm{E}$, Masson's trichrome. Sirius Red and IHC stainings were performed using standard procedures that have previously been described $[7,26]$. The following antibodies were used: cleaved Caspase-3 (R\&D systems; clone AF835), Ki-67 (Dako, M724901), F4/80 (AbD Serotec, clone A3-1), CK19 (Developmental Studies Hybridoma Bank, TROMA-III), CD45 (ebioscience, 14-0451), p-RIPK3 (Cell Signaling, \#57220) and RIP3 (gift from Genentech). Biotinylated secondary antibodies were purchased from Perkin Elmer, DAKO and Vector Laboratories. Stainings were visualized with ABC Kit Vectastain Elite (Vector Laboratories, PK6100) and DAB substrate (Dako, K3466). Stained sections were scanned using a Leica SCN400 slidescanner (Imaging facility, CECAD, Cologne) and representative snapshots were subsequently selected. For optimal visualization, levels and brightness/contrast adjustments of the pictures were equally applied using Adobe Photoshop.

IHC quantification was performed on 3-5 randomly selected high power fields (HPF) snapshots. Liver sections from 4-8 mice per genotype were analyzed. Quantification of $\mathrm{Ki}-67^{+}$and active Caspase- $3^{+}$apoptotic hepatocytes cells was performed using Image J software (Version 1.48; http://rsbweb.nih.gov/ij/). For Ki-67 quantification, selected images were spectrally unmixed and the nuclear size was defined to match the manual counts of hepatocytes per field under the microscope. The images were then analyzed using the measure function by running a macro in batch mode. Data is represented as number of proliferating hepatocytes per HPF. For cleaved Caspase 3 evaluation appropriate pixel threshold intensity was equally applied on all selected 
pictures and the total brown area was determined using measure function. Data is represented as $\%$ of stained area per HPF.

\section{Macroscopic and histopathological evaluation of liver tumors}

Livers of sacrificed mice were excised, digitally photographed with their dorsal side exposed, and weighed to calculate the liver/body weight ratio. Histopathological evaluation was performed on H\&E stained liver sections, where the number, size (diameter) and stage of tumors were assessed. For the hepatocarcinogenesis quantification, the following stages were used in ascending order of severity: No severe pathology, $\leq 5$ or $>5$ dysplastic foci/nodules per liver lobe cross-section, and high-grade dysplastic nodules and early or well-differentiated HCC. In the corresponding graphs, each bar represents the \% of livers per genotype in which the indicated stage was identified as the most advanced hepatocarcinogenesis stage.

\section{Hepatocytes, cholangiocytes and cell death assay}

Primary hepatocytes were isolated from 4-week-old mice by retrograde liver perfusion with a collagenase solution (15 $\mathrm{mg}$ Collagenase D and $2 \mathrm{mg}$ Trypsin inhibitor in EBSS) through the caval vein, as previously described [7]. Hepatocytes were cultured in DMEM (Sigma-Aldrich) containing $2 \%$ FCS, penicillin and streptomycin in collagen-coated plates. Normal mouse cholangiocytes (NMCs) are not immortalized/transformed cells that were isolated and cultured as previously described [50]. The cells maintain their strong biliary phenotype (expression of markers such as AE2, CFTR and AQP1, and characteristic primary cilium in the apical membrane) for at least 15 cell passages before going into senescence. NMCs from passages 4 to 8 were used for our described in vitro experiments.

For cell death assays, hepatocytes and NMCs were treated with the following reagents: $20 \mathrm{ng} / \mathrm{ml}$ TNF (VIB Protein Service Facility, Ghent), $10 \mu \mathrm{M}$ Birinapant (Smac mimetic, Biovision), $20 \mathrm{ng} / \mathrm{ml}$ Actinomycin D (transcription inhibitor, Sigma-Aldrich), $20 \mu \mathrm{M}$ zVAD-fmk (Pan-Caspase inhibitor, Enzo Life Sciences), $20 \mu \mathrm{M}$ Necrostatin-1s (RIPK1 kinase inhibitor, Biovision) and 2 (in NMCs) or $10 \mu \mathrm{M}$ (in primary hepatocytes) 5Z-7-Oxozeaenol (TAK1 inhibitor, Sigma-Aldrich) for $24 \mathrm{~h}$. Cell death was estimated by measuring LDH release CytoTox $96^{\circledR}$ Nonradioactive Cytotoxicity Assay kit (Promega, G1780) according to the manufacturer's instructions. The experiments were performed in triplicates using primary hepatocytes that were isolated from at least three different mice per indicated genotype. At least three independent cell death experiments were performed in NMCs.

\section{Immunoblotting}

Protein extracts were prepared by homogenizing liver tissue, primary hepatocytes, or NMCs in lysis buffer $(150 \mathrm{mM}$ $\mathrm{NaCl}, 1 \% \mathrm{NP}-40,0.1 \%$ SDS in a $50 \mathrm{mM}$ Tris buffer at $\mathrm{pH}$ 7.5) supplemented with phosSTOP phosphatase inhibitors and complete protease inhibitors (Roche). Lysates were separated by SDS-polyacrylamide gel electrophoresis (PAGE), transferred to Immobilon-P PVDF membranes (Millipore), and analyzed by immunoblotting. The following primary antibodies were used: cleaved Caspase-3 (Cell Signaling, \#9661), Caspase 3 (Cell Signaling, \#9662), RIPK1 (BD Biosciences, 610459), FADD (Millipore, 05486), RIPK3 (Enzo Life Sciences, ADI-905-242-100), MLKL (Millipore, MABC604), Caspase-8 (Enzo Life Sciences, ALX-804-447-C100), ZBP1 (Adipogen, AG-20B0010), CK-19 (Developmental Studies Hybridoma Bank, TROMA-III), Albumin (Santa Cruz, sc-46291), and GAPDH (Imgenex, IMG-5019A-1). Membranes were incubated with secondary, HRP-coupled antibodies (GE Healthcare and Jackson ImmunoResearch), followed by detection with ECL-Prime reagent (RPN 2106, GE Healthcare).

\section{Quantitative real-time polymerase chain reaction}

Isolation of total RNA from frozen whole liver tissue and cDNA synthesis was performed as previously described [7]. Quantitative real-time polymerase chain reaction (qRTPCR) was performed using gene-specific TaqMan assays (Life technologies). mRNA expression of each gene was normalized to the expression of the housekeeping gene Tbp.

\section{Statistical analysis}

For comparisons between two datasets, unpaired Student's $t$-test or Mann-Whitney $U$ test was used depending on whether the datasets fulfilled the D'Agostino \& Pearson normality test criteria or not. For comparisons of multiple datasets that followed Gaussian distribution or not, 1-way ANOVA with a post-hoc Tukey's test or a Kruskal-Wallis test with a post-hoc Dunn's test was performed, respectively. In all dot plots, horizontal lines represent the mean values, while column graphs represent the mean \pm SD. A $P$ value of less than 0.05 was considered significant $(* P \leq$ $0.05, * * P \leq 0.01, * * * P \leq 0.005)$. Statistical analysis was performed with Prism version 6.0 (GraphPad).

Acknowledgements We thank V. Dixit and Genentech for anti-RIPK3

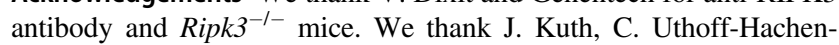
berg, E. Gareus, B. Kühnel and E. Stade for technical assistance. This work was supported by grants from Worldwide Cancer Research (award no. 15-0228) and the European Research Council (grant agreement no. 323040 to MP). VK was supported by a Marie Curie 
Career Development Fellowship (FP7-PEOPLE-2010-IEF; proposal no. 275767).

Author contributions SK-S performed genetic crosses, tissue sampling, IHC, immunoblotting, qRT-PCR, and data interpretation and drafted the manuscript. VK conducted genetic crosses, tissue sampling, IHC analysis, in vitro experiments in NMCs and hepatocytes and data interpretation. SS, $\mathrm{KH}$, and PS performed histopathological analysis of mouse livers. MA and GK provided Tak1 $1^{\mathrm{FL}}$ and $\mathrm{HW}$ Trailr ${ }^{\mathrm{FL}}$ mice. JMB provided NMCs. VK and MP coordinated the project and wrote the manuscript.

\section{Compliance with ethical standards}

Conflict of interest The authors declare that they have no conflict of interest.

Publisher's note: Springer Nature remains neutral with regard to jurisdictional claims in published maps and institutional affiliations.

\section{References}

1. Guicciardi ME, Malhi H, Mott JL, Gores GJ. Apoptosis and necrosis in the liver. Compr Physiol. 2013;3:977-1010.

2. Schwabe RF, Luedde T. Apoptosis and necroptosis in the liver: a matter of life and death. Nat Rev Gastroenterol Hepatol. 2018;15:738-52.

3. Kondylis V, Pasparakis M. RIP kinases in liver cell death, inflammation and cancer. Trends Mol Med. 2019;25:47-63.

4. Luedde T, Beraza N, Kotsikoris V, van Loo G, Nenci A, De Vos $\mathrm{R}$, et al. Deletion of NEMO/IKKgamma in liver parenchymal cells causes steatohepatitis and hepatocellular carcinoma. Cancer Cell. 2007;11:119-32.

5. Liedtke C, Bangen JM, Freimuth J, Beraza N, Lambertz D, Cubero FJ, et al. Loss of caspase- 8 protects mice against inflammation-related hepatocarcinogenesis but induces nonapoptotic liver injury. Gastroenterology. 2011;141:2176-87.

6. Ehlken H, Krishna-Subramanian S, Ochoa-Callejero L, Kondylis V, Nadi NE, Straub BK, et al. Death receptor-independent FADD signalling triggers hepatitis and hepatocellular carcinoma in mice with liver parenchymal cell-specific NEMO knockout. Cell Death Differ. 2014;21:1721-32.

7. Kondylis V, Polykratis A, Ehlken H, Ochoa-Callejero L, Straub BK, Krishna-Subramanian S, et al. NEMO prevents steatohepatitis and hepatocellular carcinoma by inhibiting RIPK1 kinase activitymediated hepatocyte apoptosis. Cancer Cell. 2015;28:582-98.

8. Vucur M, Reisinger F, Gautheron J, Janssen J, Roderburg C, Cardenas DV, et al. RIP3 inhibits inflammatory hepatocarcinogenesis but promotes cholestasis by controlling caspase-8- and JNK-dependent compensatory cell proliferation. Cell Rep. 2013;4:776-90.

9. Koppe C, Verheugd P, Gautheron J, Reisinger F, Kreggenwinkel $\mathrm{K}$, Roderburg C, et al. I kappa B kinase alpha/beta control biliary homeostasis and hepatocarcinogenesis in mice by phosphorylating the cell-death mediator receptor-interacting protein kinase 1 . Hepatology . 2016;64:1217-31.

10. Schneider AT, Gautheron J, Feoktistova M, Roderburg C, Loosen $\mathrm{SH}$, Roy S, et al. RIPK1 suppresses a TRAF2-dependent pathway to liver cancer. Cancer Cell. 2017;31:94-109.

11. Boege Y, Malehmir M, Healy ME, Bettermann K, Lorentzen A, Vucur M, et al. A dual role of caspase-8 in triggering and sensing proliferation-associated DNA damage, a key determinant of liver cancer development. Cancer Cell. 2017;32:342-59 e10.
12. Dara L, Liu ZX, Kaplowitz N. Questions and controversies: the role of necroptosis in liver disease. Cell Death Discov. 2016;2:16089.

13. Ting AT, Bertrand MJ. More to life than NF-kappaB in TNFR1 signaling. Trends Immunol. 2016;37:535-45.

14. Annibaldi A, Meier P. Checkpoints in TNF-induced cell death: implications in inflammation and cancer. Trends Mol Med. 2018;24:49-65.

15. Dondelinger Y, Jouan-Lanhouet S, Divert T, Theatre E, Bertin J, Gough PJ, et al. NF-kappa B-independent role of IKK alpha/IKK beta in preventing RIPK1 kinase-dependent apoptotic and necroptotic cell death during TNF signaling. Mol Cell. 2015;60:63-76.

16. Lafont E, Draber P, Rieser E, Reichert M, Kupka S, de Miguel D, et al. TBK1 and IKKepsilon prevent TNF-induced cell death by RIPK1 phosphorylation. Nat Cell Biol. 2018;20:1389-99.

17. $\mathrm{Xu} \mathrm{D}$, Jin $\mathrm{T}$, Zhu $\mathrm{H}$, Chen $\mathrm{H}$, Ofengeim $\mathrm{D}$, Zou $\mathrm{C}$, et al. TBK1 suppresses RIPK1-driven apoptosis and inflammation during development and in aging. Cell . 2018;174:1477-91 e19.

18. Bettermann K, Vucur M, Haybaeck J, Koppe C, Janssen J, Heymann F, et al. TAK1 suppresses a NEMO-dependent but NFkappa B-independent pathway to liver cancer. Cancer Cell. 2010;17:481-96.

19. Kellendonk C, Opherk C, Anlag K, Schutz G, Tronche F. Hepatocyte-specific expression of Cre recombinase. Genesis . 2000;26:151-3.

20. Inokuchi S, Aoyama T, Miura K, Osterreicher $\mathrm{CH}$, Kodama $\mathrm{Y}$, Miyai K, et al. Disruption of TAK1 in hepatocytes causes hepatic injury, inflammation, fibrosis, and carcinogenesis. Proc Natl Acad Sci USA. 2010;107:844-9.

21. Gautheron J, Vucur M, Reisinger F, Cardenas DV, Roderburg C, Koppe C, et al. A positive feedback loop between RIP3 and JNK controls non-alcoholic steatohepatitis. Embo Mol Med. 2014;6:1062-74.

22. Roychowdhury S, McMullen MR, Pisano SG, Liu X, Nagy LE. Absence of receptor interacting protein kinase 3 prevents ethanolinduced liver injury. Hepatology. 2013;57:1773-83.

23. Wang L, Du F, Wang X. TNF-alpha induces two distinct caspase8 activation pathways. Cell . 2008;133:693-703.

24. Dara L, Johnson H, Suda J, Win S, Gaarde W, Han D, et al. Receptor interacting protein kinase 1 mediates murine acetaminophen toxicity independent of the necrosome and not through necroptosis. Hepatology. 2015;62:1847-57.

25. Suda J, Dara L, Yang L, Aghajan M, Song Y, Kaplowitz N, et al. Knockdown of RIPK1 markedly exacerbates murine immunemediated liver injury through massive apoptosis of hepatocytes, independent of necroptosis and inhibition of NF-kappaB. J Immunol. 2016;197:3120-9.

26. Van TM, Polykratis A, Straub BK, Kondylis V, Papadopoulou N, Pasparakis M. Kinase-independent functions of RIPK1 regulate hepatocyte survival and liver carcinogenesis. J Clin Invest. 2017; 127:2662-77.

27. Afonso MB, Rodrigues PM, Simao AL, Ofengeim D, Carvalho T, Amaral JD, et al. Activation of necroptosis in human and experimental cholestasis. Cell Death Dis. 2016;7:e2390.

28. Gunther C, He GW, Kremer AE, Murphy JM, Petrie EJ, Amann $\mathrm{K}$, et al. The pseudokinase MLKL mediates programmed hepatocellular necrosis independently of RIPK3 during hepatitis. J Clin Invest. 2016;126:4346-60.

29. Pasparakis M, Vandenabeele P. Necroptosis and its role in inflammation. Nature. 2015;517:311-20.

30. Anderton H, Bandala-Sanchez E, Simpson DS, Rickard JA, Ng AP, Di Rago L, et al. RIPK1 prevents TRADD-driven, but TNFR1 independent, apoptosis during development. Cell Death Differ. 2019;26:877-89. 
31. Yang L, Inokuchi S, Roh YS, Song J, Loomba R, Park EJ, et al. Transforming growth factor-beta signaling in hepatocytes promotes hepatic fibrosis and carcinogenesis in mice with hepatocytespecific deletion of TAK1. Gastroenterology. 2013;144: 1042-54 e4.

32. Mihaly SR, Ninomiya-Tsuji J, Morioka S. TAK1 control of cell death. Cell Death Differ. 2014;21:1667-76.

33. Inokuchi-Shimizu S, Park EJ, Roh YS, Yang L, Zhang B, Song J, et al. TAK1-mediated autophagy and fatty acid oxidation prevent hepatosteatosis and tumorigenesis. J Clin Invest. 2014;124: 3566-78.

34. Pescatore A, Esposito E, Draber P, Walczak H, Ursini MV. NEMO regulates a cell death switch in TNF signaling by inhibiting recruitment of RIPK3 to the cell death-inducing complex II. Cell Death Dis. 2016;7:e2346.

35. Irrinki KM, Mallilankaraman K, Thapa RJ, Chandramoorthy HC, Smith FJ, Jog NR, et al. Requirement of FADD, NEMO, and $\mathrm{BAX} / \mathrm{BAK}$ for aberrant mitochondrial function in tumor necrosis factor alpha-induced necrosis. Mol Cell Biol. 2011;31:3745-58.

36. Shimizu Y, Peltzer N, Sevko A, Lafont E, Sarr A, Draberova H, et al. The linear ubiquitin chain assembly complex acts as a liver tumor suppressor and inhibits hepatocyte apoptosis and hepatitis. Hepatology. 2017;65:1963-78.

37. Filliol A, Piquet-Pellorce C, Le Seyec J, Farooq M, Genet V, Lucas-Clerc C, et al. RIPK1 protects from TNF-alpha-mediated liver damage during hepatitis. Cell Death Dis. 2016;7:e2462.

38. Filliol A, Piquet-Pellorce C, Raguenes-Nicol C, Dion S, Farooq M, Lucas-Clerc C, et al. RIPK1 protects hepatocytes from Kupffer cells-mediated TNF-induced apoptosis in mouse models of PAMP-induced hepatitis. J Hepatol. 2017;66:1205-13.

39. Seehawer M, Heinzmann F, D'Artista L, Harbig J, Roux PF, Hoenicke L, et al. Necroptosis microenvironment directs lineage commitment in liver cancer. Nature. 2018;562:69-75.

40. Yanger K, Zong Y, Maggs LR, Shapira SN, Maddipati R, Aiello NM, et al. Robust cellular reprogramming occurs spontaneously during liver regeneration. Genes Dev. 2013;27:719-24.
41. Eftychi C, Karagianni N, Alexiou M, Apostolaki M, Kollias G. Myeloid TAKI [corrected] acts as a negative regulator of the LPS response and mediates resistance to endotoxemia. PLoS ONE. 2012;7:e31550.

42. Schmidt-Supprian M, Bloch W, Courtois G, Addicks K, Israel A, Rajewsky K, et al. NEMO/IKK gamma-deficient mice model incontinentia pigmenti. Mol Cell. 2000;5:981-92.

43. Mc Guire C, Volckaert T, Wolke U, Sze M, de Rycke R, Waisman A, et al. Oligodendrocyte-specific FADD deletion protects mice from autoimmune-mediated demyelination. $\mathrm{J}$ Immunol. 2010;185:7646-53.

44. Dannappel M, Vlantis K, Kumari S, Polykratis A, Kim C, Wachsmuth L, et al. RIPK1 maintains epithelial homeostasis by inhibiting apoptosis and necroptosis. Nature . 2014;513:90-4.

45. Polykratis A, Hermance N, Zelic M, Roderick J, Kim C, Van TM, et al. Cutting edge: RIPK1 Kinase inactive mice are viable and protected from TNF-induced necroptosis in vivo. J Immunol. 2014;193:1539-43.

46. Newton K, Sun X, Dixit VM. Kinase RIP3 is dispensable for normal NF-kappa Bs, signaling by the B-cell and T-cell receptors, tumor necrosis factor receptor 1 , and Toll-like receptors 2 and 4. Mol Cell Biol. 2004;24:1464-9.

47. Van Hauwermeiren F, Armaka M, Karagianni N, Kranidioti K, Vandenbroucke RE, Loges S, et al. Safe TNF-based antitumor therapy following p55TNFR reduction in intestinal epithelium. J Clin Invest. 2013;123:2590-603.

48. Hao Z, Hampel B, Yagita H, Rajewsky K. T cell-specific ablation of Fas leads to Fas ligand-mediated lymphocyte depletion and inflammatory pulmonary fibrosis. J Exp Med. 2004;199:1355-65.

49. Grosse-Wilde A, Voloshanenko O, Bailey SL, Longton GM, Schaefer U, Csernok AI, et al. TRAIL-R deficiency in mice enhances lymph node metastasis without affecting primary tumor development. J Clin Invest. 2008;118:100-10.

50. Uriarte I, Banales JM, Saez E, Arenas F, Oude Elferink RP, Prieto $\mathrm{J}$, et al. Bicarbonate secretion of mouse cholangiocytes involves $\mathrm{Na}(+)-\mathrm{HCO}(3)(-)$ cotransport in addition to $\mathrm{Na}(+)$-independent $\mathrm{Cl}(-) / \mathrm{HCO}(3)(-)$ exchange. Hepatology. 2010;51:891-902. 